\title{
Comparison of Experimental and Computational Fluid Dynamics (CFD) studies of slug flow in a vertical riser
}

\author{
Abdulkadir, M. ${ }^{1 *}$, Hernandez-Perez, V. ${ }^{2}$, Lo, S. ${ }^{3}$, Lowndes, I. S. ${ }^{2} \&$ Azzopardi, B. J. ${ }^{2}$ \\ ${ }^{1}$ Department of Chemical Engineering, Federal University of Technology, Minna, Niger State, Nigeria \\ ${ }^{2}$ Process and Environmental Engineering Research Division, Faculty of Engineering, University of Nottingham \\ University Park, Nottingham, NG7 2RD, United Kingdom \\ ${ }^{3}$ CD-adapco, Trident Park, Didcot, OX11 7HJ, United Kingdom \\ *Corresponding author’s e-mail: mukhau @ futminna.edu.ng
}

\begin{abstract}
This paper presents a comparison of the results obtained from experiments and CFD studies of slug flow in a vertical riser. A series of two experimental investigations were carried out on a $6 \mathrm{~m}$ vertical pipe with a $0.067 \mathrm{~m}$ internal diameter charged with an air-silicone oil mixture. For the first set of experiments, the riser was initially full of air, and then liquid and gas flows set to liquid and gas superficial velocities $=0.05$ and 0.344 $\mathrm{m} / \mathrm{s}$, respectively, electrical capacitance tomography (ECT) and wire mesh sensor (WMS) transducers were employed. In the second one, the riser was initially full of (static) liquid, and then liquid and gas flows set to liquid and gas superficial velocities $=0.05$ and $0.344 \mathrm{~m} / \mathrm{s}$, respectively, only ECT was used. A characterization of the observed slug flow regimes was carried out. This includes the evaluation of the instantaneous distribution of the phases over the pipe cross-section, the Probability Density Function (PDF) of void fraction, time series of cross-sectional void fraction, Power Spectral Density (PSD), structure velocity of the Taylor bubble, lengths of the liquid slug and Taylor bubble and void fractions in the liquid slug and Taylor bubble. The simulation results were validated both qualitatively and quantitatively against experimental data. A reasonably good agreement was observed between the results of the experiment and CFD.
\end{abstract}

Keywords: CFD, ECT, VOF, Slug flow, air-silicone oil, riser, PDF, void fraction, PSD, Tay lor bubble length, velocity

\section{Introduction:}

Slug flow in a vertical riser is a very common flow regime under normal operating conditions of a two-phase flow facility, such as an oil production riser. One feature of slug flow is the acceleration of the liquid phase to form fast moving liquid slugs, which can carry a significant amount of liquid with high kinetic energy. This is potentially hazardous to the 
structure of the flow transport system and processing equipment due to the strong oscillating pressure produced by the mechanical momentum of the slugs.

In oil production, the presence of liquid slugs in the riser gives an irregular output in terms of gas and liquid flow at either the outlet to the system or the next processing stage. This can pose challenges to the design and operation of such flow systems. The pressure drop experienced for slug flow regimes is substantially higher when compared to other flow regimes, and consequently the maximum possible length of a liquid slug that might be encountered needs to be known. Often, slug catching devices are used to collect the slugs, and avoid any damage to the downstream equipment. For the design of such slug catchers, it is important to know what kind of slugs to anticipate. For that reason, it is important to study the behaviour of slug flow in great detail for the optimal, efficient and safe design and operation of two-phase gas-liquid flow systems.

A considerable amount of research has been devoted to the study of this two-phase flow regime. The important question of when and how these slugs are formed has received much attention from research workers: [1-5] among others. A critical review of this topic is given by Fabre and Line [6]. However, there remains much to be investigated and understand about that flow pattern. In particular, deeper investigation is needed to attain a thorough understanding of the internal structure of slug flow. Moreover, reports on slug flow behaviour with fluids which are relevant to the industry are limited. Empirical correlations and mechanistic models have been presented in the literature. These are mainly one-dimensional approaches that cannot fully characterize the flow. The limitations of one-dimensional models may be addressed by the use of Computational Fluid Dynamics (CFD). The applications of CFD to investigate multiphase flow are highly dependent on the flow pattern under study, as different closure models are needed for different flow regimes. These models 
require to be validated to gain confidence in their use. The validation of CFD models requires experimental data that characterize the important flow parameters over a range of liquid and gas flow rates.

In this work, different slug flow characteristics (e.g. void fraction in liquid slug and Taylor bubble, lengths of liquid slug and Taylor bubble, slug frequency, structure velocity) are determined using the results of experiments and the solutions to the CFD models. To validate the CFD models the results were compared against the corresponding experimental data.

\section{Experimental Methodology:}

The experimental investigations were carried out on an inclinable pipe flow rig within the Chemical Engineering Laboratories at the University of Nottingham. The details of this experimental facility may be found in Azzopardi et al. [7] and [8-10]. In brief: the experimental test section of the facility consists of a transparent acrylic pipe of $6 \mathrm{~m}$ length and $0.067 \mathrm{~m}$ internal diameter. The test pipe section may be rotated on the rig to allow it to lay at any inclination angle of between -5 to $90^{\circ}$ to the horizontal. For the experiments reported in this paper the rig test pipe section was mounted as a vertical riser (an inclination of $90^{0}$ to the horizontal). It is worthy of mention that full-experimentation in risers of this magnitude and other larger ones is expensive and therefore a more cost-effective approach for exploring the behaviour of two-phase flow in these risers is by using validated CFD model simulations.

The resultant flow patterns obtained from two sets of experimental campaigns involving airsilicone oil flow rates were recorded using electrical capacitance tomography (ECT) and wire mesh sensor (WMS). A detailed description of theory behind the ECT technology can be found in [7], and [11-12]. In this study, a ring of two measurement electrodes were placed around the circumference of the riser at a given height above the injection portals at the 
bottom of the $6 \mathrm{~m}$ riser section. The use of two such circumferential rings of sensor electrodes, located at a specified distance apart (also known as twin-plane sensors), enabled the determination of the rise velocity of any observed Taylor bubbles and liquid slugs. The twin-plane ECT sensors were placed at a distance of 4.4 and $4.489 \mathrm{~m}$ upstream of the airsilicone oil mixer, and injection portal, located at the base of the riser. A flow chart of the various experimental measurements and the calculated parameters that characterise the flow are presented in Table 1.

The capacitance WMS placed at $4.92 \mathrm{~m}$ away from the mixing section, described in detail by da Silva et al. [13], can image the dielectric components of the two-phase mixture in the pipe by measuring, rapidly and continually, the capacitances of the passing fluid at the crossing points in the mesh. This capacitance signal is a measure of the amount of silicone oil, and thus indicates the local phase composition in the grid cell.

The physical experiments were conducted as a series of two campaigns: (1) pipe initially full of air, and then liquid and gas flows set to liquid and gas superficial velocities of 0.05 and $0.344 \mathrm{~m} / \mathrm{s}$, respectively and (2) the second involved pipe initially full of (static) liquid, and then liquid and gas flows set to liquid and gas superficial velocities of 0.05 and $0.344 \mathrm{~m} / \mathrm{s}$, respectively (the same as for the subsequent CFD simulation models). 
Table 1: Flowchart of the collection and processing of the experimental measurements used to obtain the parametric characterisation of the slug flow regime

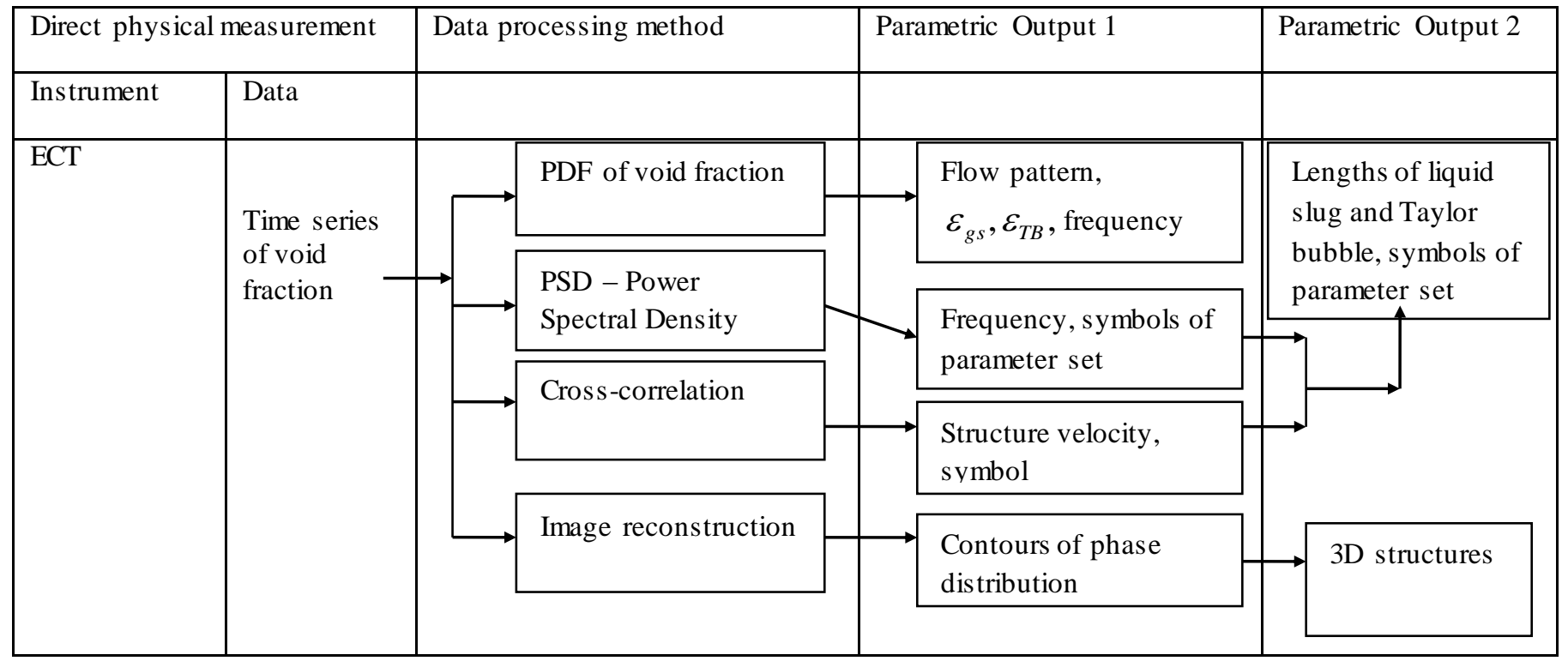

\subsection{Gas-liquid mixing section}

In the design of the physical experimental rig, it was ensured that the mixing section of the air and silicone oil phases took place in such a way as to reduce flow instability. Flow stability was achieved by using a purpose built mixing device, to provide maximum time for the twophase flow to develop. The mixing device is made from PVC pipe as shown in Figure 2. The silicone oil enters the mixing chamber from one side and flows around a perforated cylinder through which the air is introduced through a large number of $3 \mathrm{~mm}$ diameter orifices. This arrangement ensures that the gas and liquid flows were well mixed at the entry to the test section. The inlet volumetric flow rates of the liquid and air were determined by a set of rotameters located above a set of valves on the two inlet feed flow pipes.

The introduction of the air and liquid flows at the inlet to the CFD models was defined as a velocity-inlet boundary at which the mixture velocity and the liquid volume fraction are specified. The mixture velocity profile is assumed to be uniform. This approach requires no 
additional experimental knowledge about the formation of the liquid slugs to formulate the numerical simulation.

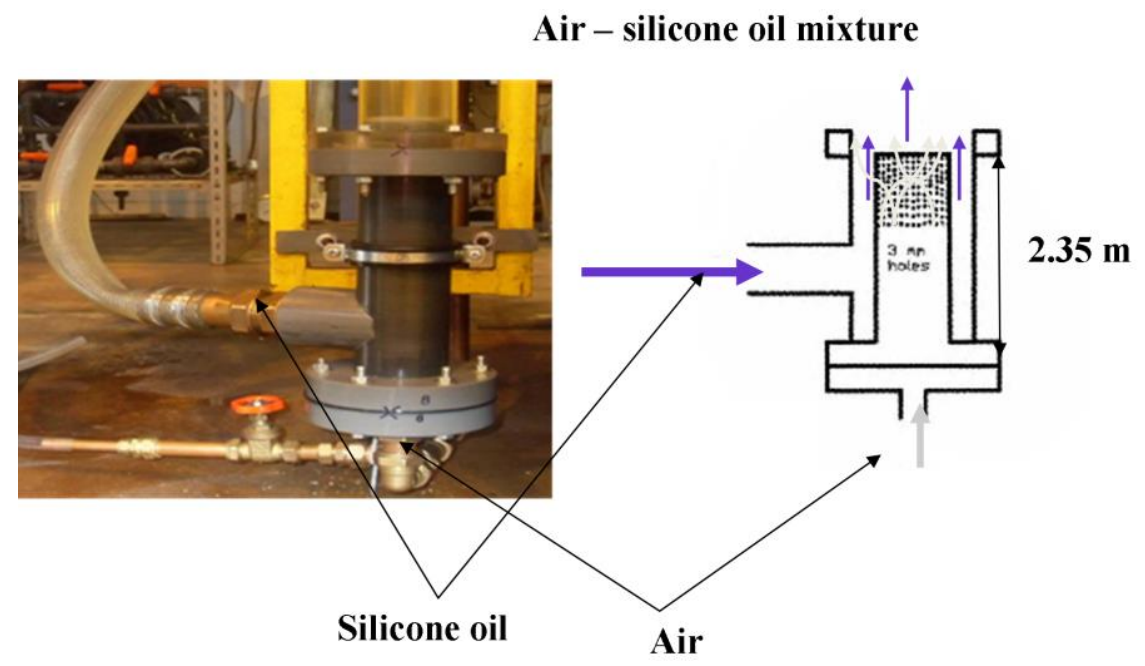

Figure 2: Air-silicone oil mixing section

\section{CFD Model:}

Parallel to the execution of the physical experiments, the construction and solution of CFD models were carried out. The aim of the numerical simulations was to investigate the potential application of the multiphase flow models, built in the commercial CFD codes Star$\mathrm{CD}$ and Star-CCM+. The Star-CD code employs the Finite Volume method to numerically discretize the computational flow domain. In the present work, isothermal motion of an incompressible two-phase flow is considered. The condition of slug two-phase flow has been simulated with the Volume of Fluid (VOF) method of Hirt and Nichols [14].The movement of the modelled gas-liquid interface is tracked based on the distribution of, $\alpha_{G_{1}}$, the volume fraction of gas in a computational cell; where $\alpha_{G}=0$, is a liquid cell and $\alpha_{G}=1$ in a gas phase cell, [14]. Therefore, the gas-liquid interface exists in the cell where $\alpha_{G}$ lies between 0 and 1. 


\subsection{Computational domain:}

In order for the simulation to produce meaningful results, it was important to ensure that the geometry of the flow domain faithfully represented the experimental arrangement. Hence, a full 3-Dimensional flow domain, as shown in Figure 1, was considered based on the fact that the flow simulated has been found to be axisymmetric according to the conclusions of the previous experimental studies of Azzopardi et al. [7] and [10] and In the present work, three CFD measurement sections were located at positions similar to those of the experimental work, namely, at distances of $4.4 \mathrm{~m}, 4.489 \mathrm{~m}$ and $4.92 \mathrm{~m}$ above the base of the riser. Here, the locations $4.4 \mathrm{~m}$ and $4.489 \mathrm{~m}$ represent the two electrical capacitance tomography (ECT) planes, whilst $4.92 \mathrm{~m}$ the wire mesh sensor (WMS). Air and silicone oil are injected at the inlet section of the pipe, then the two-phase mixture flows upwards through the vertical riser pipe, finally discharges through the outlet at atmospheric pressure. The relevant fluids properties are shown in Table 2.

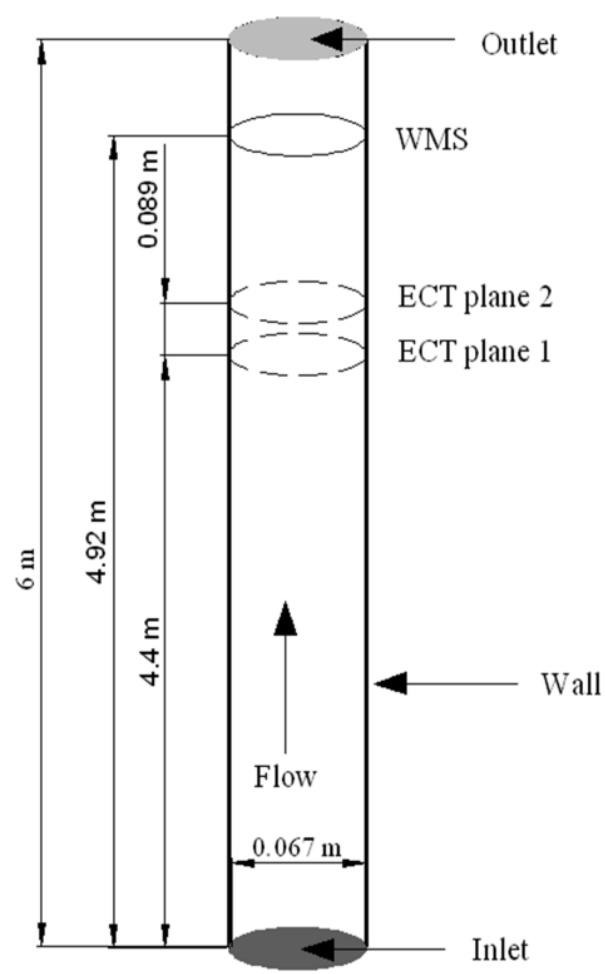

Figure 1: 3-D geometry of the computational flow domain showing the location of the recording sections that correspond to the locations of the experimental measurement transducers. 
Table 2: Properties of the fluids

\begin{tabular}{cccc}
\hline Fluid & Density $\left(\mathrm{kg} / \mathrm{m}^{3}\right)$ & Viscosity $(\mathrm{kg} / \mathrm{ms})$ & Surface tension (N/m) \\
\hline Air & 1.18 & 0.000018 & 0.02 \\
\hline Silicone oil & 900 & 0.0053 & \\
\hline
\end{tabular}

\subsection{Grid generation:}

The model riser flow geometry was built and meshed with Star-CD, then imported into Star$\mathrm{CCM}+$, where the computation and post-processing of the results were performed. The geometries of the mesh employed is the butterfly grid (O-grid), which has been successfully employed by [10], and [15-16]. Figure 3 shows the mesh for the riser used for the CFD simulation. It uses a Cartesian mesh at the centre of the pipe combined with a cylindrical one around it. According to Hernandez-Perez [15], the O-grid (butterfly grid) allows for a good representation of the boundary layer and it is adequately stretched along the longitudinal axis. It was essential in this work to have a reasonably fine grid close to the wall, with a thickness of $0.0000123 \mathrm{~m}$. A growth function was used to build the grid with these properties where the first grid was fixed to a distance of $10^{-6} \mathrm{~m}$ to ensure a $\mathrm{y}+<1$ and to properly resolve the boundary layer close to the wall surface. The $y+$ is a non-dimensional wall distance that describes how coarse or fine a mesh is for a wall-bounded flow. In this particular case, a fine grid is required to properly capture the sub layer between the laminar flow (near the wall region) $(y+\leq 5)$, the transition $(5 \leq y+\leq 30)$ and the turbulent flow (in the bulk region) $(y+\geq 30)$. 


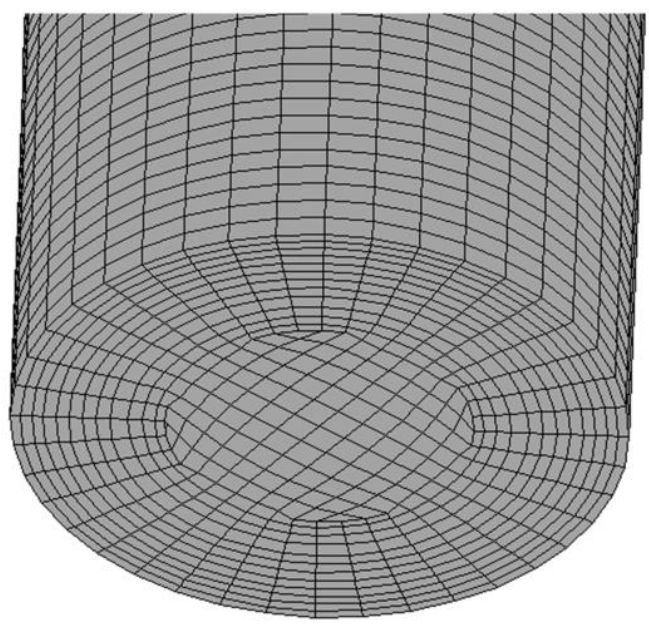

Figure 3: Computational mesh used for simulations

\subsection{Governing equations}

Slug flow was modelled using the Volume of Fluid (VOF) method with a High Resolution Interface Capturing Scheme (HRIC) based on the Compressive Interface Capturing Scheme for Arbitrary Meshes (CISCAM) introduced by [18] and enhanced by [19].

The continuity and momentum equations represented respectively by equations (1) and (2) for two-phase flow through the flow domain are:

$$
\begin{aligned}
& \frac{\partial \rho}{\partial t}+\frac{\partial \rho u_{i}}{\partial x_{i}}=0 \\
& \frac{\partial \rho u_{j}}{\partial t}+\frac{\partial \rho u_{i} u_{j}}{\partial x_{i}}=-\frac{\partial P}{\partial x_{j}}+\frac{\partial}{\partial x_{i}} \mu\left(\frac{\partial u_{i}}{\partial x_{j}}+\frac{\partial u_{j}}{\partial x_{i}}\right)+\rho g_{j}+F_{j}
\end{aligned}
$$

where, $u_{i}$ and $x_{i}$ denote, respectively, the velocity component and the co-ordinate in the direction $i$ ( $i=1,2$ or 3$), t$, being the time; and through the resolution of the momentum equation shared by the two considered fluids, $P, g$ and $F$ indicate, respectively, the pressure, the gravitational acceleration and the external force per unit volume. 
The tracking of the phase indicator function and the identification of the location and shape of the interface between the gas-liquid phases are accomplished by solving the volume fraction continuity equation for each phase, expressed as equation (3):

$$
\frac{\partial \alpha_{q}}{\partial t}+\frac{u_{i} \partial\left(\alpha_{q}\right)}{\partial x_{i}}=0
$$

where,

and the volume fractions of all phases as shown in equation (4) sum to unity in each control volume:

$$
\sum_{q=1}^{n} \alpha_{q}=1
$$

where, $q$ is the liquid or gas phase.

The properties of the $q$ th phase are used in the transport equations when the computational cell is completely controlled by the $q$ th phase. At the interface between the phases, the mixture properties are determined based on the volume fraction weighted average, and the density and viscosity can be expressed as:

$$
\rho=\alpha_{2} \rho_{2}+\left(1-\alpha_{2}\right) \rho_{1}
$$

$$
\mu=\alpha_{2} \mu_{2}+\left(1-\alpha_{2}\right) \mu_{1}
$$

where, the phases are represented by the subscripts 1 and 2 and if the volume fraction of the phase 2 is known, the $\rho$ and $\mu$ in each cell can be determined.

In the present work, the Continuum Surface Force (CSF) model proposed by Brackbill et al. [20] was used to model the surface tension. With this model, the addition of surface tension to the VOF model calculation results in a source term in the momentum equation. 


\subsection{Turbulence model}

In order to simulate turbulence, the standard $k-\varepsilon$ model, Launder and Spalding [21] was used for this study as suggested by the multiphase flow studies of Ramos-Banderas et al. [22] and [23]. The model is described by the following elliptic equations required as closure for the Reynolds Averaged Navier Stokes (RANS) equations:

$$
\begin{aligned}
& \rho_{u_{j}} \frac{\partial k}{\partial x_{j}}=\frac{\partial}{\partial x_{j}}\left(\frac{\mu_{t}}{\sigma_{k}} \frac{\partial k}{\partial x_{j}}\right)+\mu_{t} \frac{\partial u_{j}}{\partial x_{i}}\left(\frac{\partial u_{i}}{\partial x_{j}}+\frac{\partial u_{j}}{\partial x_{i}}\right)-\rho \varepsilon \\
& \rho_{u_{j}} \frac{\partial \varepsilon}{\partial x_{j}}=\frac{\partial}{\partial x_{j}}\left(\frac{\mu_{t}}{\sigma_{\varepsilon}} \frac{\partial \varepsilon}{\partial x_{j}}\right)+C_{1} \mu_{t} \frac{\varepsilon}{k} \frac{\partial u_{j}}{\partial x_{i}}\left(\frac{\partial u_{i}}{\partial x_{j}}+\frac{\partial u_{j}}{\partial x_{i}}\right)-C_{2} \frac{\varepsilon}{k} \rho \varepsilon
\end{aligned}
$$

In the above equations, $k$ is the turbulent kinetic energy; $\varepsilon$ is the dissipation rate of $k . \sigma_{k}, \sigma_{\varepsilon}$, $C_{1}$ and $C_{2}$ are constants whose values are 1.0,1.3, 1.44 and 1.92 respectively, $u_{i}$ is the $i$ component of the fluid velocity $u, x_{j}$ is the $j$ spatial coordinate. The fluid viscosity must be corrected for turbulence in the Navier-Stokes equations by employing an effective viscosity $\mu_{\text {eff }}=\mu+\mu_{t}$ where $\mu$ is the dynamic viscosity and $\mu_{t}$ is the turbulent viscosity.

The numerical solution of these sets of equations (1-8) was performed using the software package Star-CCM+. A second order discretization scheme was used to determine the fluxes at the control volume faces required by the VOF model.

\subsection{Boundary and initial conditions:}

All solid boundary walls were assumed to possess a no slip boundary condition, where $v=0$ relative to the wall and the standard wall function approach based on the Launder and Spalding [21] was used. At the flow inlet at the base of the riser, the mixture superficial velocity, $U_{M}$, defined as the sum of liquid and gas superficial velocities $\left(U_{S L}+U_{S G}\right)$ is specified. Also specified are the homogeneous volume fraction for the liquid $\left(U_{S L} / U_{M}\right)$ and gas $\left(U_{S G} / U_{M}\right)$. The flow inlet values for turbulent kinetic energy, $k$, and its dissipation 
rate, $\varepsilon$, are estimated using the following equations proposed by Launder and Spalding [29]:

$$
\begin{aligned}
& k_{i n}=\frac{3}{2} I^{2} U_{i n}{ }^{2} \\
& \varepsilon_{i n}=2 k_{i n}^{3 / 2} / d \\
& I=\frac{0.16}{\operatorname{Re}^{1 / 8}}
\end{aligned}
$$

Where $d$ is the internal pipe diameter, and $I$ the turbulence intensity for fully developed pipe flow.

The volume fraction and density of each phase were both specified at the riser inlet as a homogeneous mixture. It is worthy of mention that the volume fraction of gas at the riser inlet is different from void fraction. The latter cannot be calculated analytically based on the fact that it is a function of different operational (liquid and gas properties, flow pattern, etc) and geometric properties (i.e. pipe diameter, pipe inclination, etc). At the flow outlet at the top of the riser, the remaining variables are transported out of the computational domain with zero average static pressure so that the mass flow balance is satisfied.

At $\mathrm{t}=0$ seconds, all velocity components are set to $0 \mathrm{~m} / \mathrm{s}\left(t=t_{0} \hat{n} \cdot \bar{v}=V_{0}\right)$ and the initial condition was the riser full of (static) liquid. This initial condition eases the convergence process. In addition, an initial guess for the turbulent kinetic energy and the dissipation rate were applied in the simulation.

A surface average monitor were located at $4.4 \mathrm{~m}, 4.489 \mathrm{~m}$ and $4.92 \mathrm{~m}$ corresponding to ECTplane 1, ECT-plane 2 and WMS, respectively at three stations of the riser to avoid any inlet and outlet effects and to ensure that the slug flow is fully developed. This surface monitor determines the void fraction of air in these sections.

The operating conditions were specified as being standard atmospheric pressure $(101.3 \mathrm{kPa})$ 
and temperature $20^{\circ} \mathrm{C}$. Gravity effects are accounted for and the acceleration due to gravity to be $-9.81 \mathrm{~m} / \mathrm{s}^{2}$ on the vertical.

\subsection{Solution algorithm:}

In order to numerically solve the system of governing partial differential equations, discretization of the equations has been carried out using a Finite Volume Method (FVM) with an algebraic segregated solver and co-located grid arrangement, as implemented in Star$\mathrm{CCM}+[17]$. In this grid arrangement, pressure and velocity are both stored at cell centres. Details of the discretization (FVM) can be in Versteeg and Malalasekera [24]. Since Star$\mathrm{CCM}+$ uses a segregated solver for the VOF model, the continuity and momentum equations need to be linked. Various techniques are reported in the literature. However, the SemiImplicit Method for Pressure-Linked Equations (SIMPLE) algorithm, (Patankar and Spalding [25]), is applied as it produces a fast and convergent solution. In addition, the iterative solver was further improved by the use of an Algebraic Multigrid (AMG) technique to yield a better convergence rate.

All simulations in this work are performed under time dependent conditions. Under relaxation factors of $0.3,0.7$ and 0.8 respectively, were applied on pressure, momentum and turbulence kinetic energy parameters, as recommended by [17]. The residuals were set to $10^{-4}$ to ensure a converged solution.

\subsection{Mesh independence study:}

In order to identify the minimum mesh density to ensure that the solution is independent of the mesh resolution, a mesh sensitivity analysis has been carried out in the construction and analysis of the CFD model. In the mesh independence study, a computational domain of $1 \mathrm{~m}$ length was used as this length is sufficient to carry out a test on the performance of the mesh with quite reasonably computational effort. Six 3-Dimensional meshes were investigated in 
the present study as shown in Figure 4. The mesh sensitivity study is performed with a constant ratio $\frac{\Delta t}{\Delta x}=1 \times 10^{-4}$ and the mesh sizes of $24,000,36,000,54,600,76,800,84,000$ and 102,600 cells. The meshes were tested with an inlet flow condition (mixture superficial velocity, $U_{M}=U_{S L}+U_{S G}=0.05+0.344=0.394 \mathrm{~m} / \mathrm{s}$ and homogeneous void fraction $=U_{S G} / U_{M}$ $=0.87$ ). An initial condition of flow domain full of (static) liquid was used.

Since slug flow is characterized by void fraction fluctuation, one aspect that is interesting to look at is the time trace of cross-sectional average void fraction.

In order to determine the time series of the void fraction, the following procedure similar to that used by Hernandez-Perez [15] was performed: a cross-sectional plane is defined across the measurement location and an area-weighted average value of the void fraction is calculated. The area-weighted average of the void fraction is computed by dividing the summation of the product of the air volume fraction and facet area by the total area of the surface as follows:

$\frac{1}{A} \int \varepsilon A=\frac{1}{A} \sum_{i=1}^{n} \varepsilon\left|A_{i}\right|$

Finally the value of average void fraction in the cross-sectional plane is recorded for every time step.

The velocity of the Taylor bubble, $U_{N}$ is given by the relation of Nicklin et al. [3]:

$U_{N}=1.2\left(U_{S L}+U_{S G}\right)+0.35 \sqrt{g D}$

A calculation was performed to compare the performance of these meshes. The time calculated for the bubble to reach the measurement section $(0.5 \mathrm{~m})$ turned out to be 0.66 
seconds. The plot of the time history of the void fraction for the six meshes is shown in Table 3.

From Table 3, it can be observed that meshes 5 (84,000 cells) and 6 (102,600 cells) perform well as the time the Taylor bubble got to the measurement location is closer to the one predicted by the theoretical expression. Here, the \% error is 1.4.

The $\%$ error is evaluated as follows:

$\%$ error $=\left|\frac{X_{\text {analytical }}-X_{\text {simulated }}}{X_{\text {analytical }}}\right|$

Where $X$ is the time average of the variable for which the error is computed. The purpose of this is to compare the predictions once the code has reached a steady-state.

It can be concluded that for a given flow condition, the residence time of a fluid particle in a cell $(t=x / u)$ decreases as the mesh density increases and that the finer the mesh is, the narrower the error between predicted (simulated) and analytical solution becomes.

An insight into the effect of mesh density can also be obtained from the probability density function (PDF) of void fraction that was successfully employed by Hernandez-Perez [15] for his mesh independence studies. An examination of the plots of the PDF of void fraction shows that when the mesh is too coarse a refinement in the mesh can have a remarkable influence on the results, as depicted in Table 3. Therefore, it can be concluded that the mesh 5 with 84000 cells is adequate, as the change in the results produced is very small when the number of cells is increased to 102600 , and it requires less computational effort than the 102600 cells. 


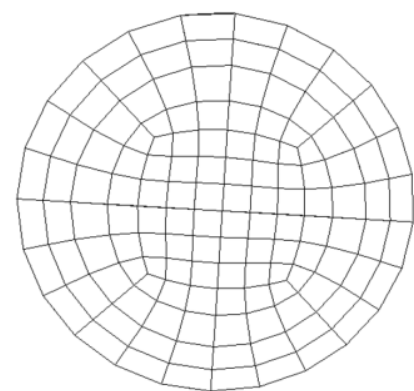

(a)

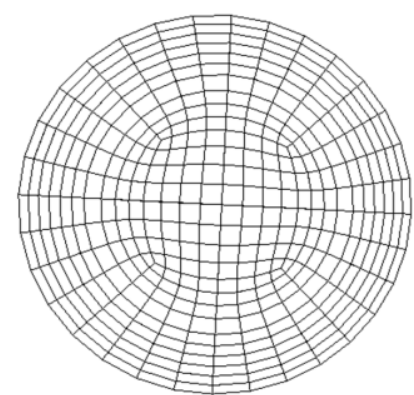

(d)

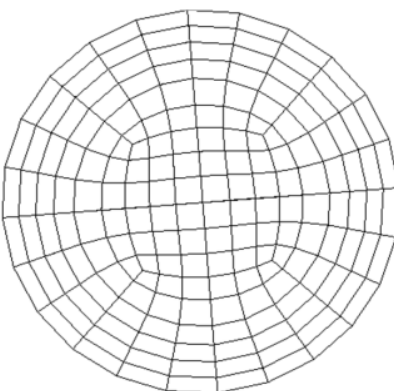

(b)

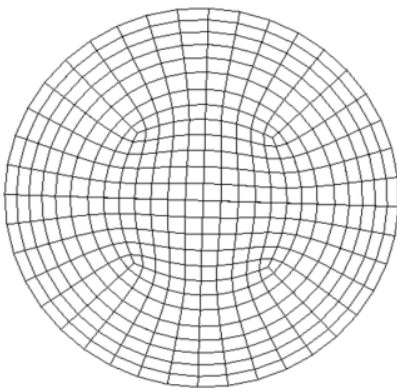

(e)

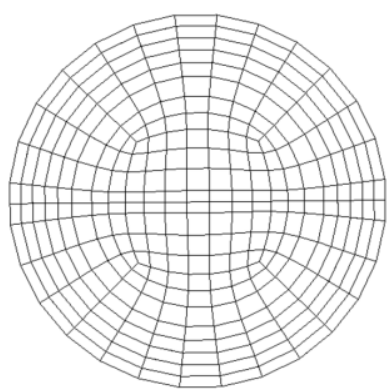

(c)

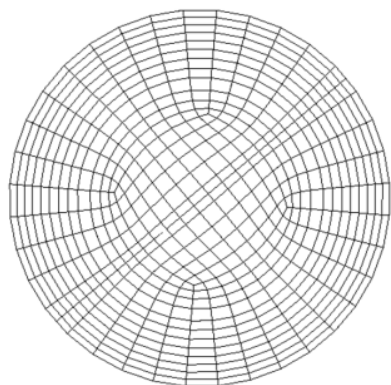

(f)

Figure 4: Cross-sectional view of different sizes of computational grid used for mesh independent study (a) 26400 cells (b) 36000 cells (c) 54,600 cells (d) 76,800 cells (e) 84,000 cells (f) 102,600 cells. Liquid and gas superficial velocities $=0.05$ and $0.344 \mathrm{~m} / \mathrm{s}$, respectively. An initial condition of riser full of (static) liquid was used.

Table 3: The results obtained from the CFD mesh independence studies. Liquid and gas superficial velocities $=0.05$ and $0.344 \mathrm{~m} / \mathrm{s}$, respectively. An initial condition of riser full of (static) liquid was used.

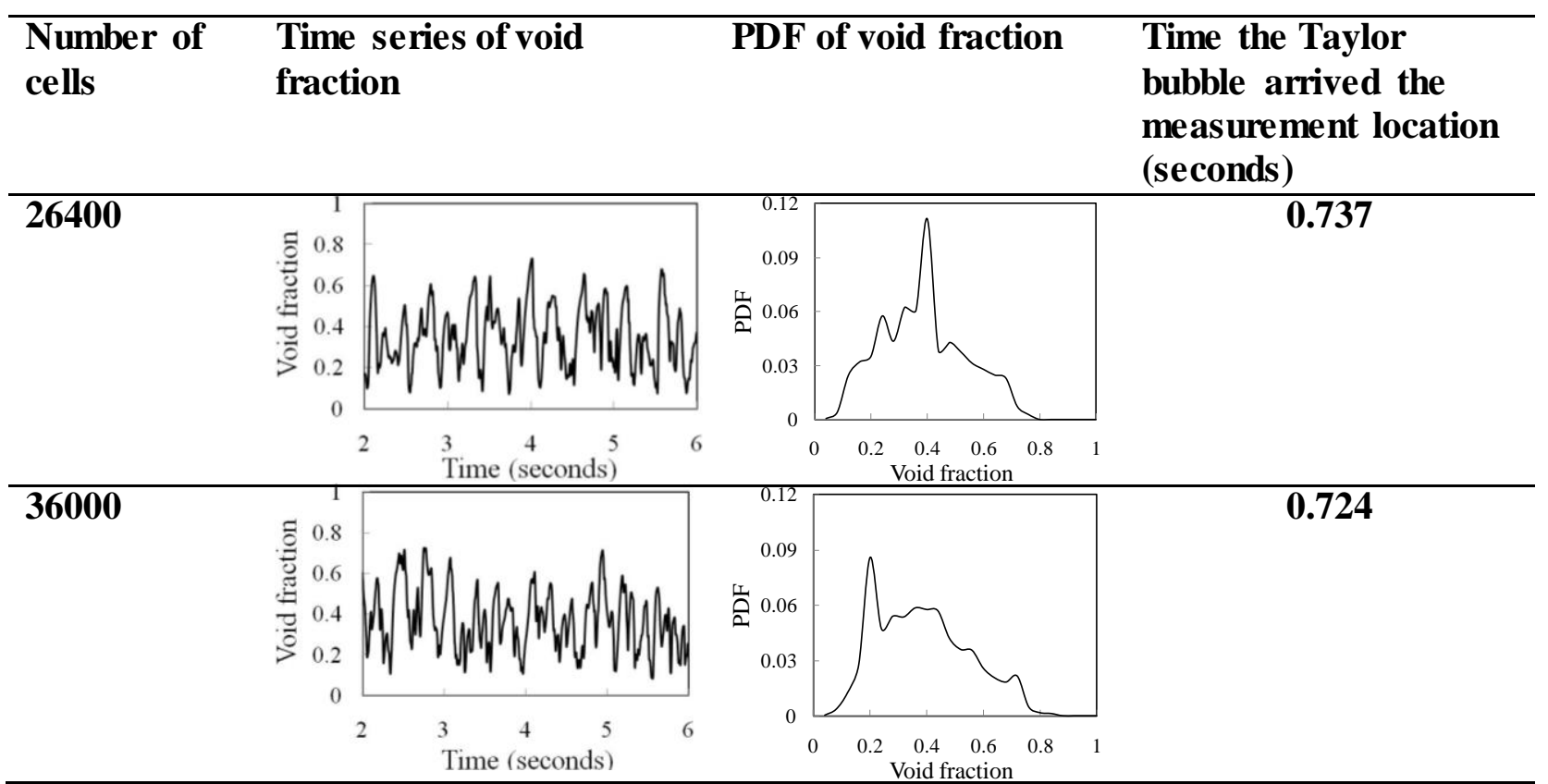




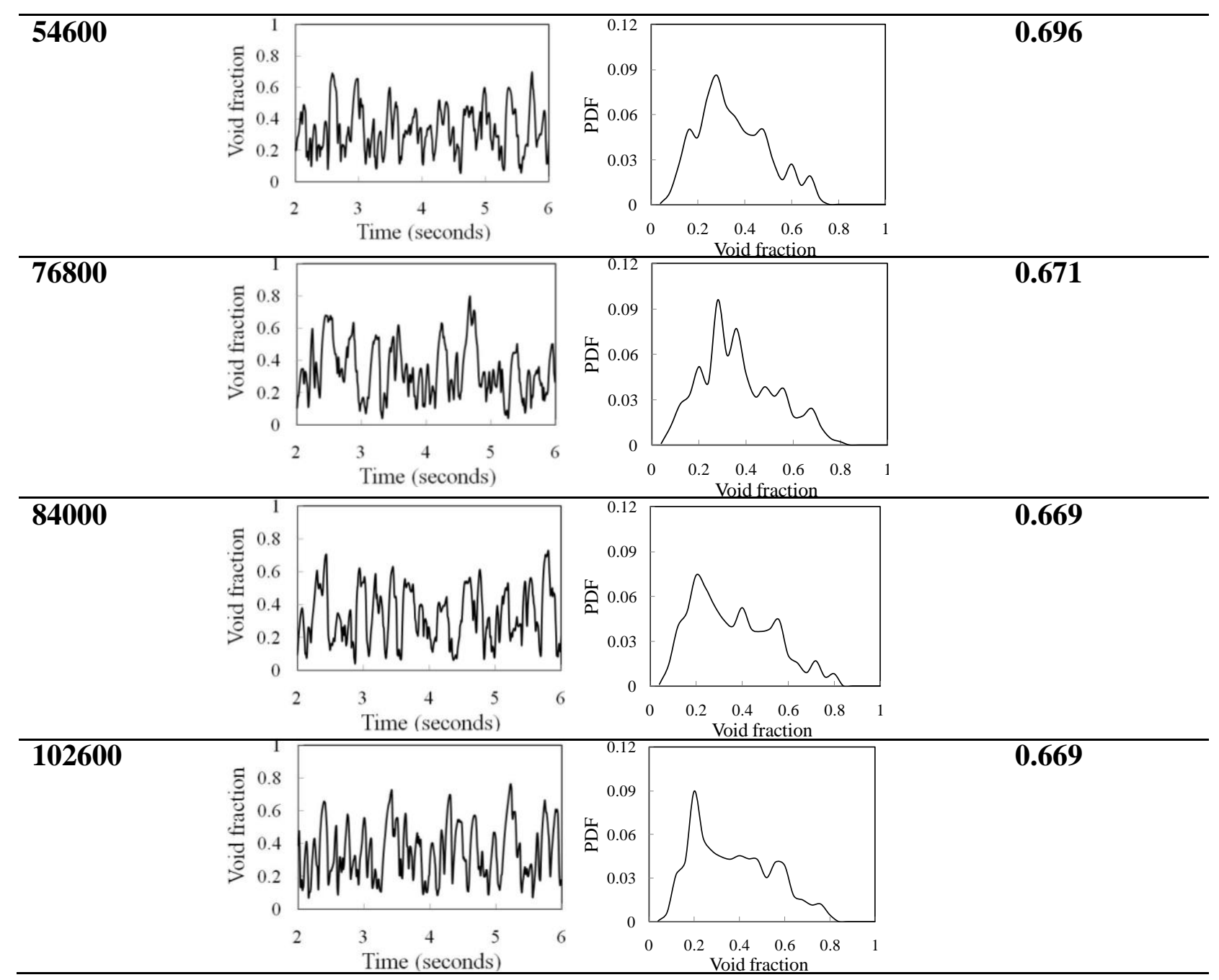

\subsection{Flow development:}

A fully developed flow is defined as one when the flow pattern does not change with the distance downstream. Flow development in the vertical riser was studied using CFD and the results are presented and discussed. The advantage of the CFD simulation compared to the physical experiment is the possibility to record the void fraction time series at many measurement sections along the pipe. Also, due to physical limitations in the length of the rig, the question that we are going to address here is whether a sufficient pipe length (often quoted in terms of pipe diameter) had been provided so that observations taken at the end of the pipe could be considered to be a true representation of a fully developed flow situation. 
Table 4: Interrogating flow development in a vertical $67 \mathrm{~mm}$ internal diameter and $6 \mathrm{~m}$ long riser. Riser initially full of (static) liquid, and the liquid and gas flows set to liquid and gas superficial velocities of 0.05 and $0.344 \mathrm{~m} / \mathrm{s}$, respectively

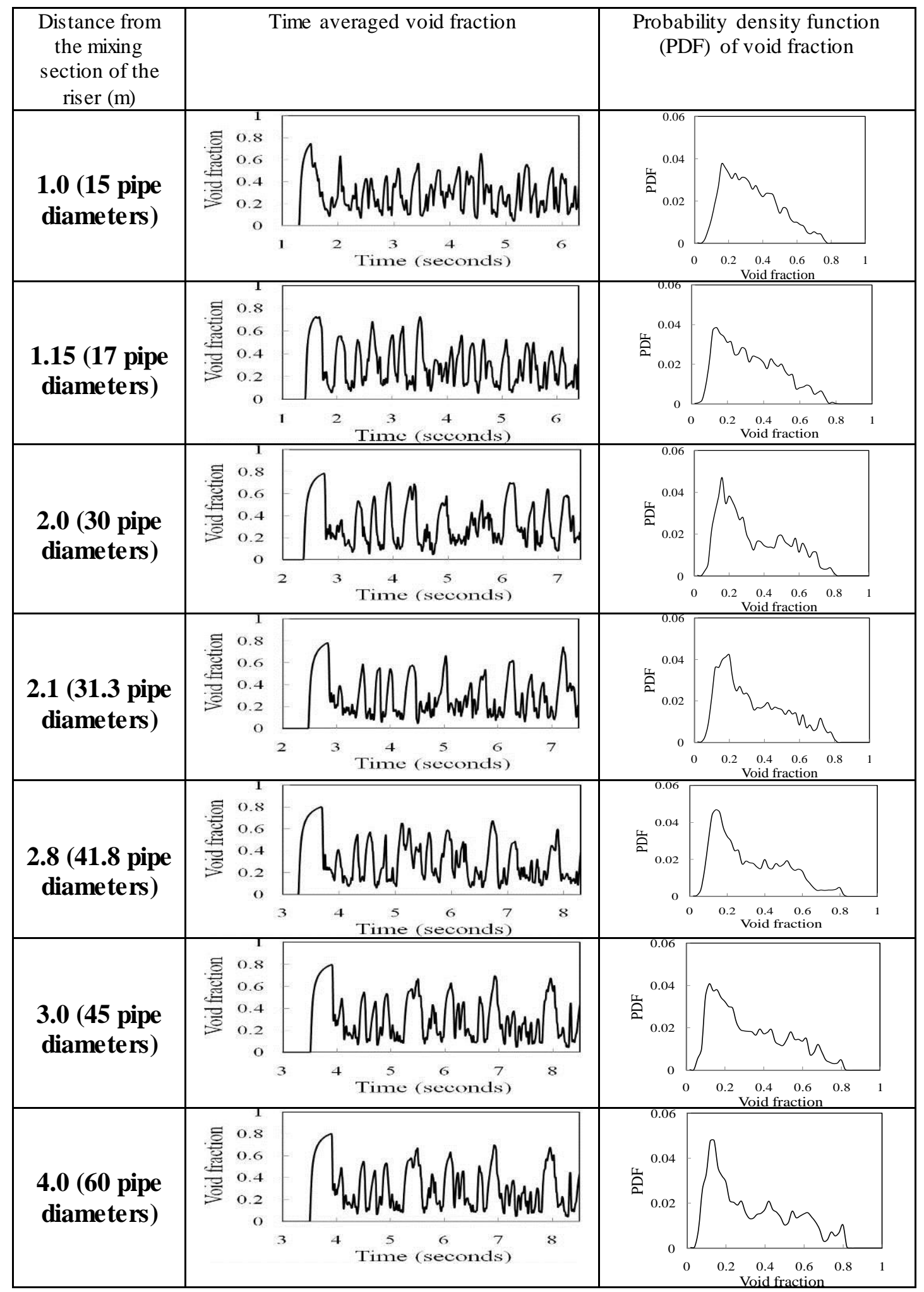




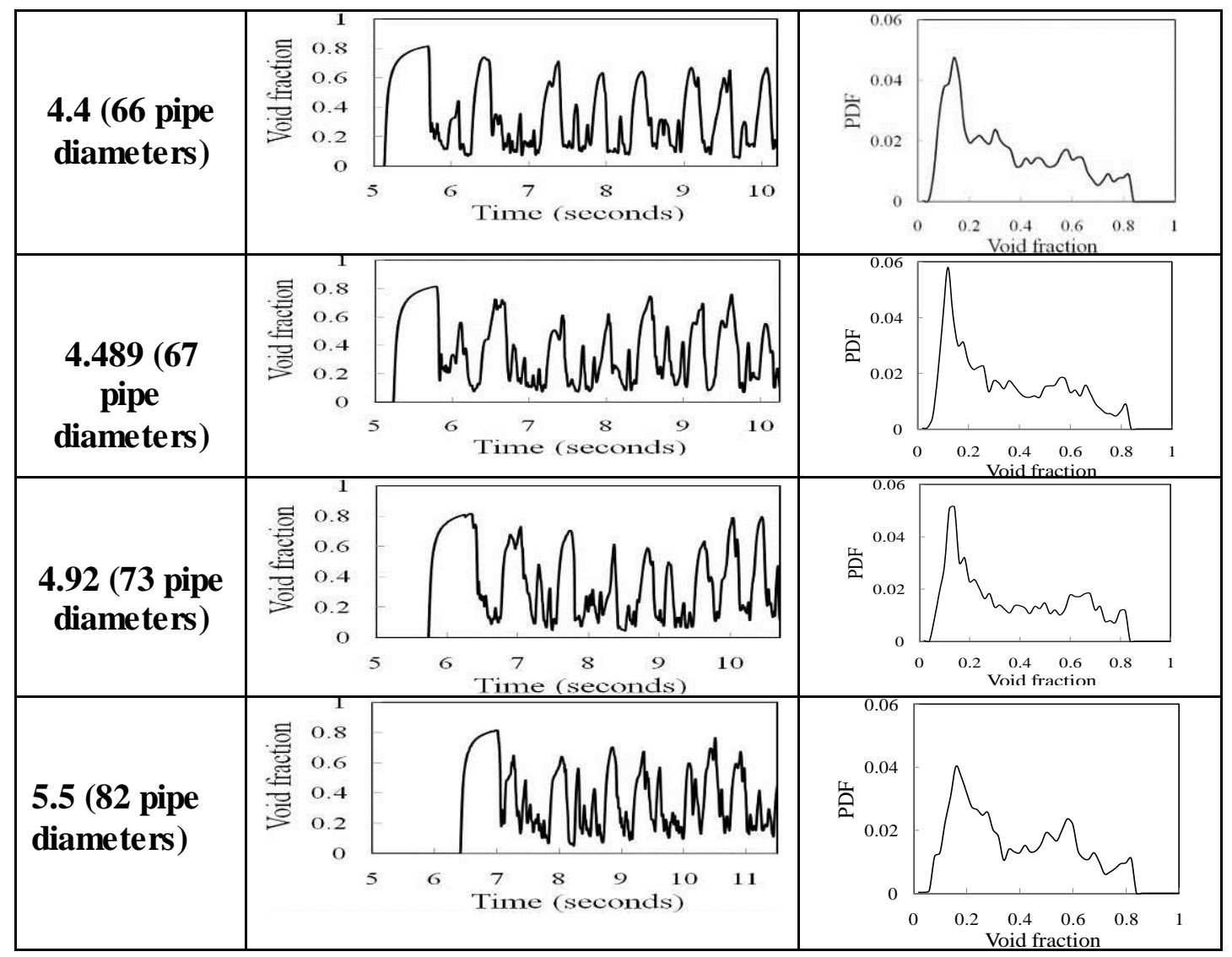

Time series of void fraction, and probability density function (PDF) of void fraction obtained from the CFD simulation are used to assess the change in flow characteristics with distance.

Table 4 shows simulation results of time varying void fraction and PDF of void fraction derived from the eleven measurement locations at liquid and gas superficial velocities of 0.05 and $0.344 \mathrm{~m} / \mathrm{s}$, respectively. The simulations were performed within a flow domain of $6 \mathrm{~m}$ long vertical pipe (the same length as the one used in the experiment) with the measurement sections located as indicated in the table.

It can be observed from the time series of void fraction shown in Table 4 that the length of the large bubbles (Taylor bubbles) increases with axial distance. This can be explained by the occurrence of bubble coalescence. The PDF of the time series of void fraction at $1.0 \mathrm{~m}$, just downstream of the two-phase mixing section, shows a single peak at low void fraction with a 
broadening tail down to higher void fraction. It also shows that the results obtained from 1.0 $\mathrm{m}$ are initially affected by entrance effects. This is further reinforced by the time trace of void fraction. With the time series of void fraction showing a maximum void fraction of 0.78 while the PDF of void fraction depicting a single peak at about 0.16 , void fraction with a tail down to 0.8 . The flow patterns begin to change to slug flow at a distance of about $2.8 \mathrm{~m} \mathrm{(42}$ pipe diameters) from the mixing section. At a distance of $2.8 \mathrm{~m}$ from the mixing section, both the time series and PDF of void fraction have taken the shape of slug flow. Though, it becomes more apparent at $4.0 \mathrm{~m}$ from the mixing section.

It is worthy of mention that at a distance of 4.0 to $5.5 \mathrm{~m}$ as depicted in Table 4, the PDF of void fraction show the traditional features of slug flow; a double peak. One peak at lower void fraction represents liquid slug whilst the one at higher void fraction, Taylor bubble. On the other hand, the time series of void fraction also show large bubbles separated by smaller ones. It can be concluded that between, 4.0 to $5.5 \mathrm{~m}$, that flow is fully developed based on the fact that the flow remains quite similar, i.e. not changing with distance from 4.0 to $5.5 \mathrm{~m}$. This corresponds to approximately 60 to 82 pipe diameters. It is in view of this development that we decided to locate our experimental measuring instruments at 4.4 (66 pipe diameters), 4.489 (67 pipe diameters) and $4.92 \mathrm{~m}$ (73 pipe diameters) corresponding to the ECT plane1, ECT-plane 2 and WMS.

\section{Results and discussion:}

The study will begin by providing a qualitative comparison between CFD simulations and experiment based on different methods of initially introducing fluid into the riser. For the CFD, the riser was initially full of (static) liquid, and then liquid and gas flows set to liquid and gas superficial velocities of 0.05 and $0.344 \mathrm{~m} / \mathrm{s}$, respectively whilst for experiment, the riser was initially full of air, and then liquid and gas flows set to same flow rates as for the 
CFD. The number of cells used for the CFD calculation is 500,000. The results of the comparison showed that the method of introducing the fluid into the riser ceases to be an issue once the flow reaches steady-state, fully developed. And that the comparison between CFD and experiment when steady-state is reached is reasonably good. Thereafter, a detailed quantitative comparison between CFD and experiments was made based on same method of initially introducing full (static) liquid into the riser. It is worth mentioning that only the ECT is used here. WMS was not used here based on the fact that it has a single plane (velocity cannot be determined) and as such cannot be used to characterize slug flow. It is worth mentioning however, that a dual WMS can be used for such a task. The liquid and gas superficial velocities $=0.05$ and $0.344 \mathrm{~m} / \mathrm{s}$, respectively for both CFD and experiment. Here, again the comparison is reasonably good.

\subsection{Qualitative comparison between CFD and experiment:}

As a starting point, the raw experimental data will be plotted in the form of time series of void fraction, PDF of void fraction and PSD of void fraction, see Figure 5. The data is collected at three measurement locations, ECT-plane 1, ECT-plane 2 and WMS. These locations correspond respectively to $4.4 \mathrm{~m}, 4.489 \mathrm{~m}$ and $4.92 \mathrm{~m}$ from the two-phase flow mixer. The data is obtained after an interval of 60 seconds.

It can be observed from the figure that as the flow reaches steady-state, the shape of the PDF and PSD of void fraction for both the CFD and experiment are similar. Both CFD and experimental PDF predict slug flow as the flow pattern, according to the definition of Costigan and Whalley [26]. According to them, slug flow is a flow pattern characterised by a PDF graph with two peaks, one at lower void fraction (liquid slug) and the other one at higher void fraction, Taylor bubble. 


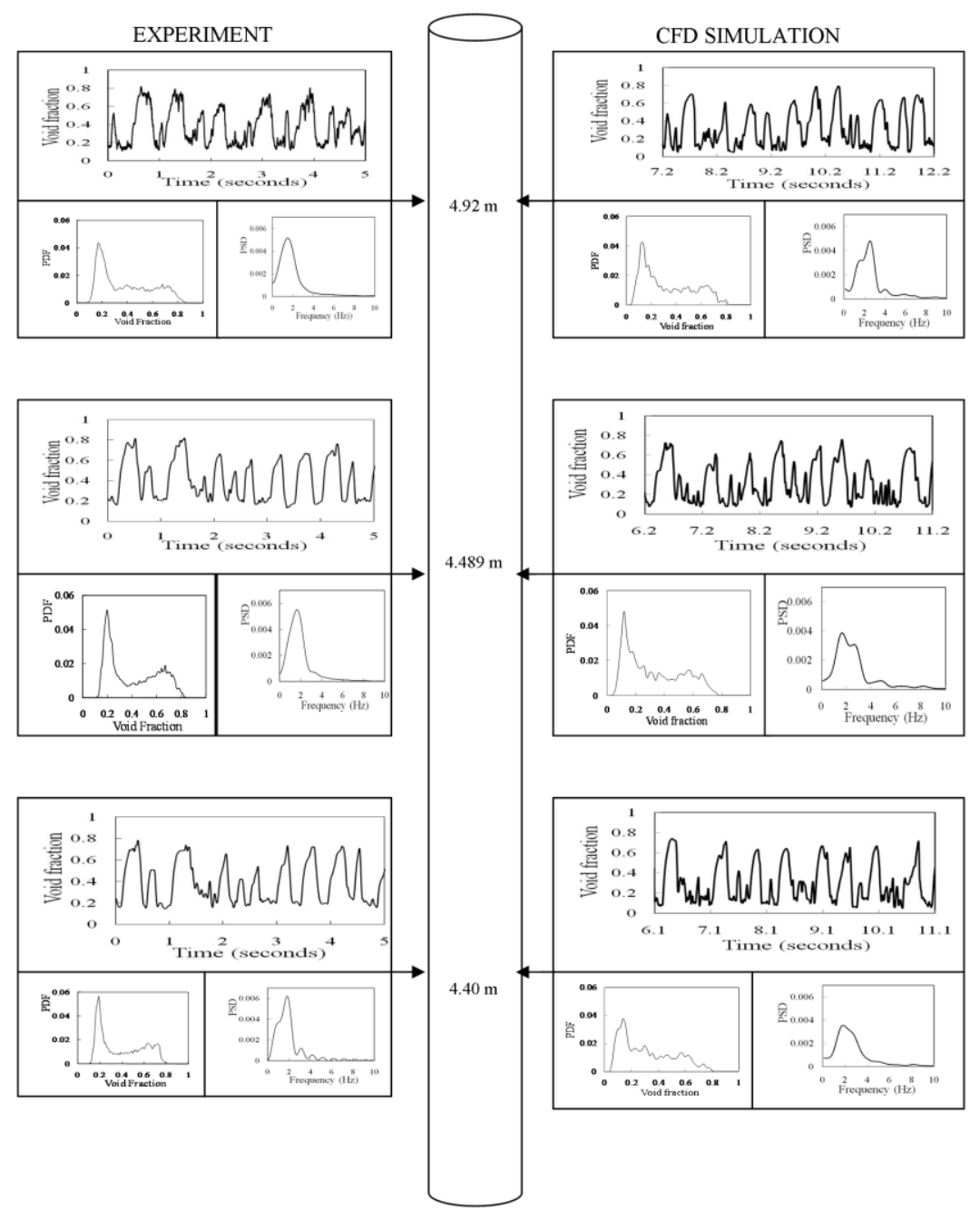

Figure 5: Comparison between experimental data and CFD simulation results at liquid and gas superficial velocities of 0.05 and $0.344 \mathrm{~m} / \mathrm{s}$, respectively. The initial conditions are riser full of (static) liquid and riser full of air, for CFD and experiment, respectively. Locations $4.4 \mathrm{~m}, 4.489 \mathrm{~m}$ and $4.92 \mathrm{~m}$ corresponds to ECT-plane 1, ECT-plane 2 and WMS, respectively.

The contours of phase distribution reported in Figures 6 (a-d) and Figures 7 (a-d) for the Taylor bubble obtained from both CFD and experiment show that the CFD results are in better agreement with those obtained from the WMS. On the contrary, the comparison between the CFD and ECT is poor.

It is worth mentioning that it is difficult to measure experimentally the velocity for these conditions due to the presence of the bubbles and the highly turbulent flow field. However, this has been successfully modelled and is represented in Figure 8, by means of velocity 
vectors. From the figure, three regions can be observed from the velocity vectors: the Taylor bubble, falling film and the wake region. Interestingly, the Taylor bubble can be seen moving vertically upwards whilst the liquid film on the other hand is moving downwards. A similar observation was reported by [4] and [5]. The falling film with some entrained bubbles drop into the wake region and a vortex region is created. Furthermore, the liquid film and some of the entrained bubbles are subsequently carried upwards by the incoming gas phase. This behaviour is similar to that observed by Fernandes et al. [4] and [27] who worked on slug flow in a vertical pipe using air-water as the model fluid. They claimed that the bubbles in the liquid slug rise due to entrainment in the wake of the Taylor bubble and that much of this entrained gas is swept around a vortex in the Taylor bubble wake and may coalesce with the trailing Taylor bubble.

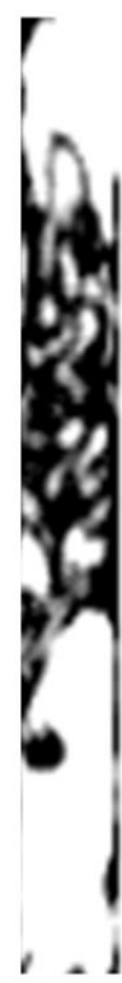

(a)

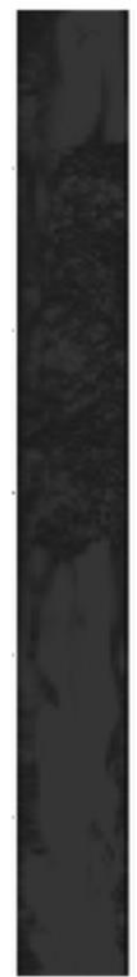

(b)

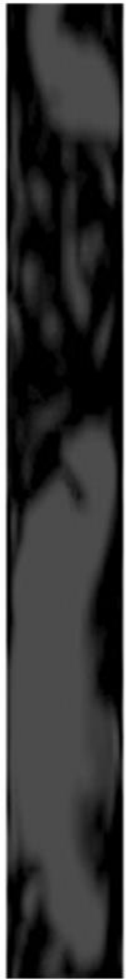

(c)

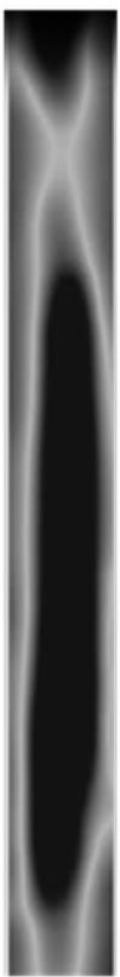

(d)

Figure 6: Comparison of contours of phase distribution at liquid and gas superficial velocities of 0.05 and $0.344 \mathrm{~m} / \mathrm{s}$, respectively for between (a) CFD and (b) WMS and for (c) CFD and (d) ECT. For the CFD and WMS comparison, the liquid and gas phases are represented by red and blue colours, respectively. On the contrary, blue represents gas phase for the ECT. The initial conditions are riser full of (static) liquid and riser full of air, for CFD and experiment, respectively. 


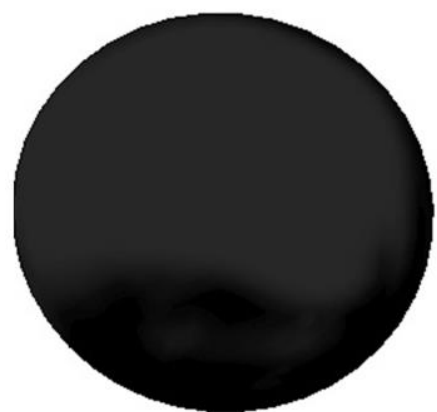

(a)

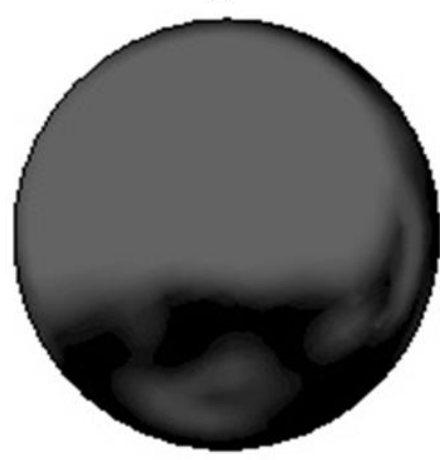

(c)

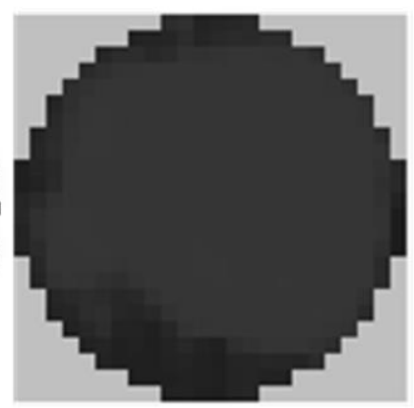

(b)

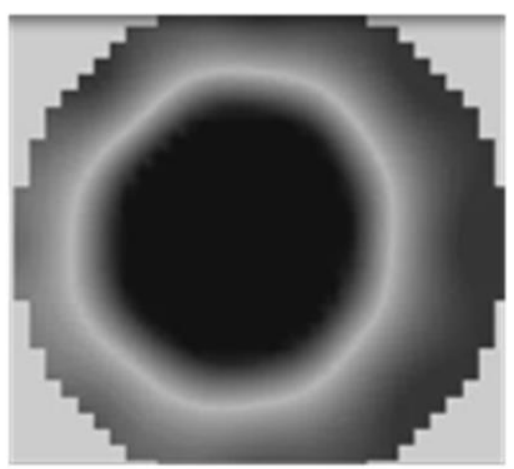

(d)

Figure 7: Contours of phase distribution (cross-sectional void fraction of gas) for the Taylor bubble obtained at liquid and gas superficial velocities of 0.05 and $0.344 \mathrm{~m} / \mathrm{s}$, respectively from (a) CFD and (b) WMS and for (c) CFD and (d) ECT. For the CFD and WMS comparison, the liquid and gas phases are represented by red and blue colours, respectively. On the contrary, blue represents gas phase for the ECT. The initial conditions are riser full of (static) liquid and riser full of air, for CFD and experiment, respectively.

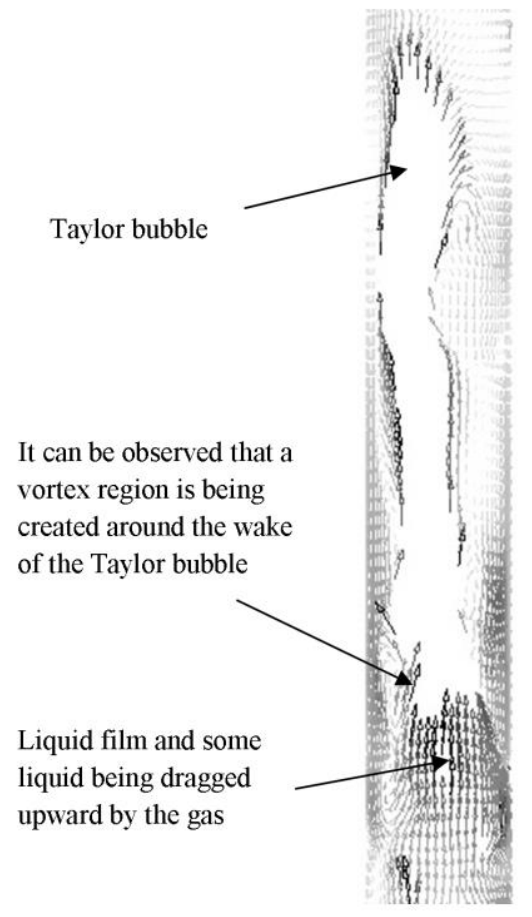

(a)

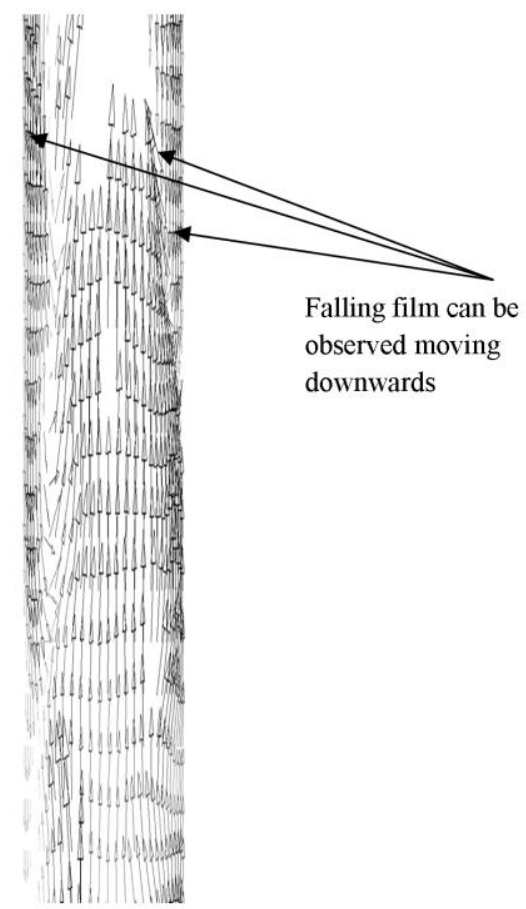

(b)

Figure 8: Velocity field around the (a) Taylor bubble (b) Wake region of the Tay lor bubble at liquid and gas superficial velocities of 0.05 and $0.344 \mathrm{~m} / \mathrm{s}$, respectively obtained from CFD. The initial conditions are riser full of (static) liquid 


\subsection{Quantitative comparison between CFD and experiment:}

The experimental data was obtained over an interval of 60 seconds whilst for the CFD, 16 seconds. Readings were taken when the Taylor bubble arrived at the measurement sections. Figure 9 shows a typical plot of a large trailing Taylor bubble (start-up) and leading train of Taylor bubbles (steady-state).

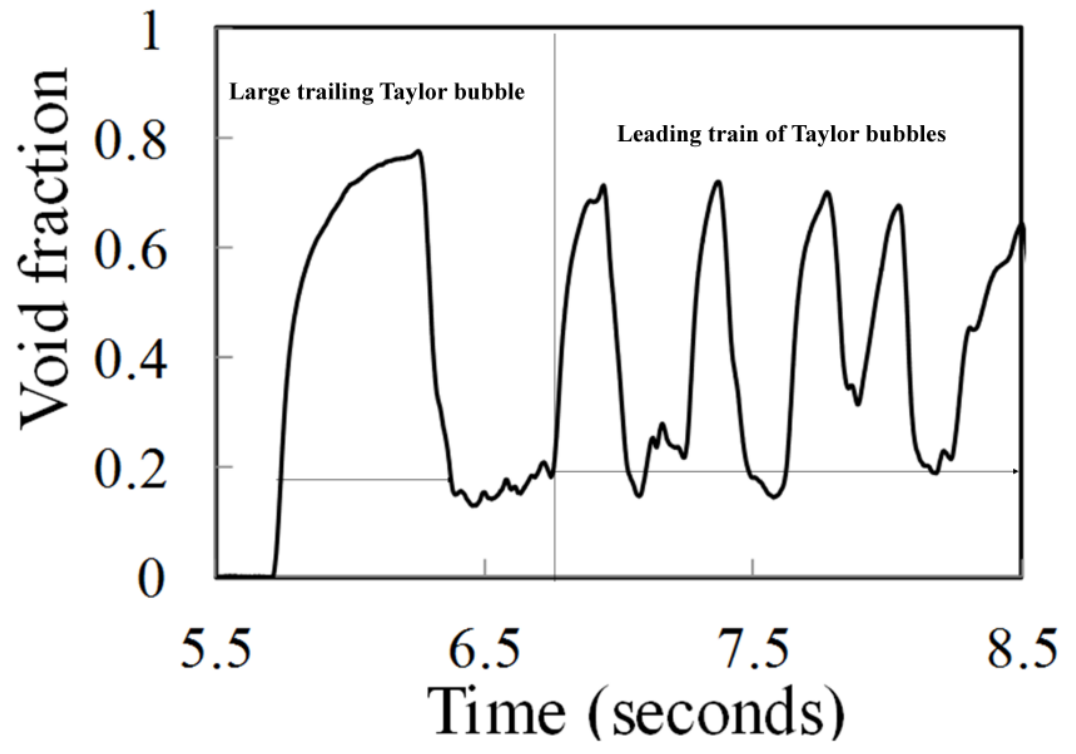

Figure 9: A plot showing a combination of a large trailing Taylor bubble (start-up) and leading train of smaller Taylor bubbles (steady-state) at liquid and gas superficial velocities $=0.05$ and $0.344 \mathrm{~m} / \mathrm{s}$, respectively). The initial condition for both CFD and experiment is riser full of (static) liquid.

A detailed methodology for the determination of these parameters can be found in Abdulkadir et al. [28]. A comparison will finally be made between CFD and experiment based on static pressure. The errors between experimental measurement and predictions are listed in Tables 5 and 6 . The error \% is evaluated as follows:

Error $=\left|\frac{X_{\text {experimental }}-X_{\text {simulated }}}{X_{\text {experimental }}}\right| \times 100$

Where $X$ is the time average of the variable for which the error is computed. The purpose is to compare the predictions once the code has reached a steady-state. 
Table 5a: Comparison between the CFD and experiments for the large trailing Tay lor bubble (Start-up) at liquid and gas superficial velocities of 0.05 and $0.344 \mathrm{~m} / \mathrm{s}$, respectively). The initial condition for both CFD and experiment is riser full of (static) liquid.

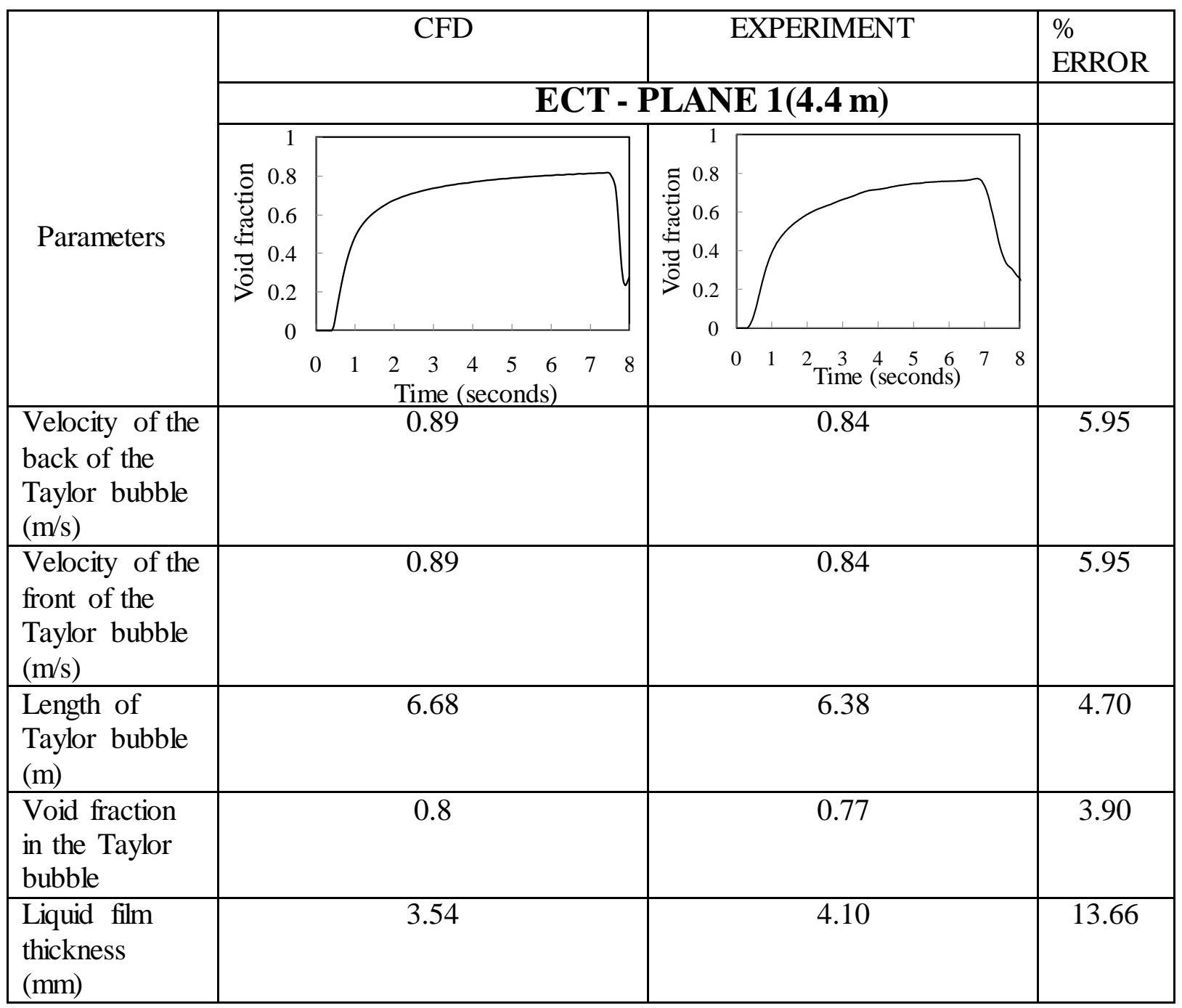

Table 5b: Comparison between the CFD and experiments for the large trailing Taylor bubble (Start-up) at liquid and gas superficial velocities of 0.05 and $0.344 \mathrm{~m} / \mathrm{s}$, respectively). The initial condition for both CFD and experiment is riser full of (static) liquid.

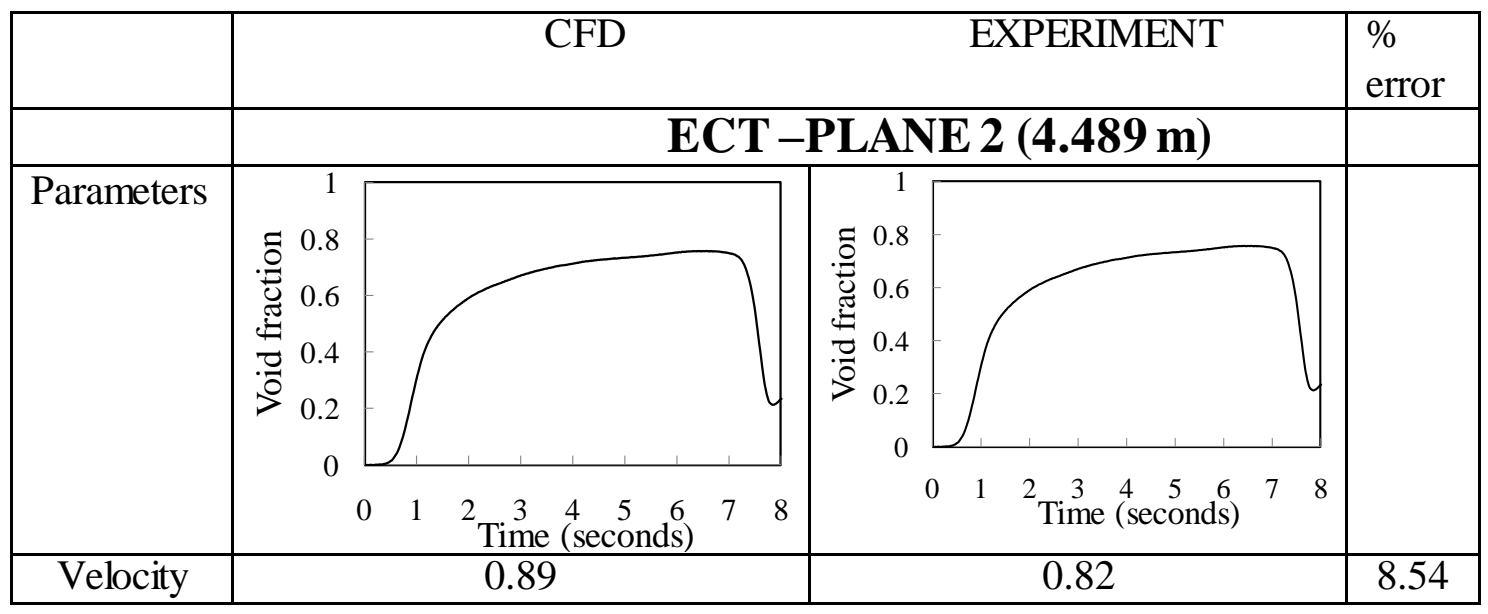




\begin{tabular}{|c|c|c|c|}
\hline $\begin{array}{c}\text { of the back } \\
\text { of the } \\
\text { Taylor } \\
\text { bubble } \\
\text { (m/s) }\end{array}$ & 0.89 & 0.82 & \\
\hline $\begin{array}{c}\text { Velocity } \\
\text { of the } \\
\text { front of } \\
\text { the Taylor } \\
\text { bubble } \\
\text { (m/s) }\end{array}$ & 0.68 & & 8.54 \\
\hline $\begin{array}{c}\text { Length of } \\
\text { slug unit } \\
\text { (m) }\end{array}$ & 0.80 & 6.23 & 7.22 \\
\hline $\begin{array}{c}\text { Void } \\
\text { fraction in } \\
\text { the Taylor } \\
\text { bubble }\end{array}$ & & & \\
\hline $\begin{array}{c}\text { Liquid } \\
\text { film } \\
\text { thickness } \\
\text { (mm) }\end{array}$ & 3.54 & 0.76 & \\
\hline
\end{tabular}

Tables $5 \mathrm{a}$ and $5 \mathrm{~b}$ presents a summary of the quantitative comparison between CFD and experiment in terms of different characteristics of slug flow in the riser. It can be concluded that the best degree of agreement between CFD and experiments in terms of slug flow characterization for the large trailing Taylor bubble is the void fraction in the Taylor bubble while the least is the liquid film thickness.

The velocity of the back and front of the Taylor bubble from the CFD compares very well with experiment. The length of the Taylor bubble for the CFD also compares well with the experiment. The void fraction in the Taylor bubble for the CFD and experiment are also compared, for this case the CFD prediction is quite accurate. The liquid film thickness was also determined from the CFD and experiment. For the CFD, the liquid film thickness obtained is $3.54 \mathrm{~mm}$ while $4.10 \mathrm{~mm}$ for the experiment which means CFD under predicted the liquid film thickness by $13.66 \%$. 
As the large Taylor bubble reaches the ECT-plane 2 (Table 5b), a similar comparison of the slug flow characterisation was also carried out. The velocity of the large trailing Taylor bubble from CFD also compares well with experiment. As expected, the length of the Taylor bubble also dropped for the experiment but remains unchanged for the CFD. The values of the void fraction in the Taylor bubble and liquid film thickness for the experiment changed from $(0.77$ and $4.10 \mathrm{~mm})$ to $(0.76$ and $4.30 \mathrm{~mm})$ but remain unchanged for the CFD.

For the leading Taylor bubble (Table 6b), it can be concluded that the best degree of agreement in terms of comparison between CFD and experiment is the length of the Taylor bubble while the least, void fraction in the liquid slug.

Table 6a: Comparison between the CFD and experiments for the leading Tay lor bubble (steady-state)/ (fully developed) at liquid and gas superficial velocities of 0.05 and $0.344 \mathrm{~m} / \mathrm{s}$, respectively). The initial condition for both CFD and experiment is riser full of (static) liquid.

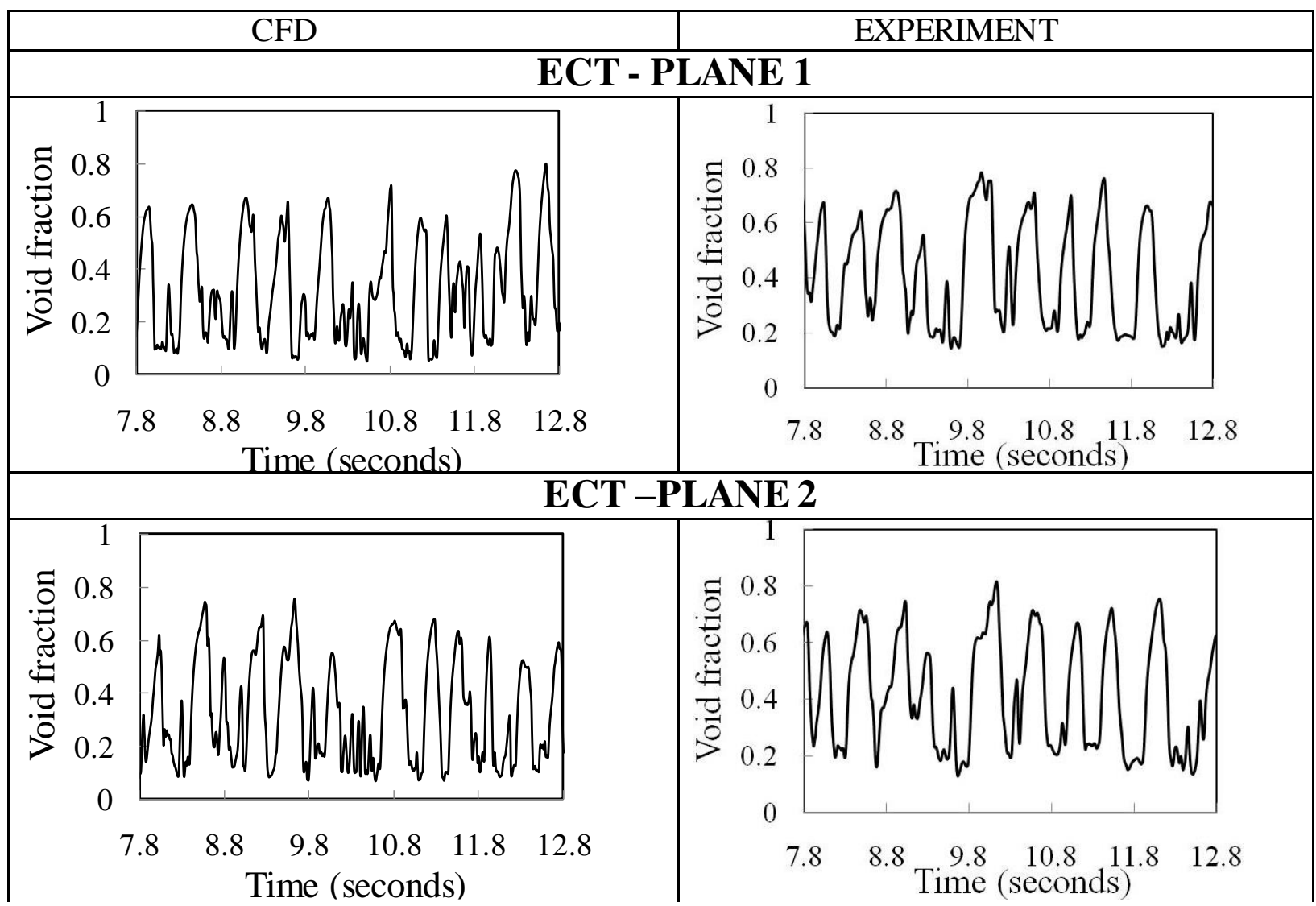

Table 6b: Comparison between the CFD and experiments for the leading Tay lor bubble (steady-state)/ (Fully developed) at liquid and gas superficial velocities of 0.05 and $0.344 \mathrm{~m} / \mathrm{s}$, respectively). The initial condition for both CFD and experiment is riser full of (static) liquid. 
Table 6b: Comparison between the CFD and experiments for the leading Tay lor bubble (Fully developed)

\begin{tabular}{|c|c|c|c|c|c|c|}
\hline Slug & \multicolumn{2}{|c|}{ (CFD) } & \multicolumn{2}{|c|}{ Experiment } & \multicolumn{2}{|c|}{$\%$ error } \\
\hline Parameter & Plane 1 & Plane 2 & Plane 1 & Plane 2 & Plane 1 & Plane 2 \\
\hline $\begin{array}{l}\text { Void fraction } \\
\text { in liquid slug }\end{array}$ & 0.14 & 0.13 & 0.17 & 0.16 & 17.6 & 18.75 \\
\hline $\begin{array}{c}\text { Void fraction } \\
\text { in Taylor } \\
\text { bubble }\end{array}$ & 0.60 & 0.56 & 0.65 & 0.62 & 7.69 & 9.68 \\
\hline Frequency & 1.8 & 2.40 & 2.0 & 2.0 & 9.6 & 20 \\
\hline $\begin{array}{c}\text { Translational } \\
\text { velocity of } \\
\text { the Taylor } \\
\text { bubble }\end{array}$ & \multicolumn{2}{|c|}{1.48} & \multicolumn{2}{|c|}{1.59} & \multicolumn{2}{|c|}{6.9} \\
\hline $\begin{array}{l}\text { Length of the } \\
\text { slug unit (m) }\end{array}$ & \multicolumn{2}{|c|}{0.82} & \multicolumn{2}{|c|}{0.80} & \multicolumn{2}{|c|}{2.5} \\
\hline $\begin{array}{l}\text { Length of the } \\
\text { Taylor bubble } \\
\text { (m) }\end{array}$ & \multicolumn{2}{|c|}{0.5} & \multicolumn{2}{|c|}{0.49} & \multicolumn{2}{|c|}{2.04} \\
\hline $\begin{array}{l}\text { Length of the } \\
\text { liquid slug } \\
\text { (m) }\end{array}$ & \multicolumn{2}{|c|}{0.32} & \multicolumn{2}{|c|}{0.31} & \multicolumn{2}{|c|}{3.23} \\
\hline $\begin{array}{l}\text { Peak of time } \\
\text { series of void } \\
\text { fraction }\end{array}$ & 0.77 & 0.74 & 0.76 & 0.78 & 1.3 & 5.13 \\
\hline
\end{tabular}

The maximum height of the peak of the void fraction from the time trace of void fraction and slug frequency for the CFD compares well with those from experiment. The time of passage of the Taylor bubble from ECT-plane 1 to 2 based on CFD and an experiment is 0.1 seconds. Both CFD and experiment predict the flow pattern as slug flow, same flow pattern as for plane 1. However, the appearance of slug flow according to Table $6 \mathrm{a}$ is more obvious than for 
plane 1. This may be due to the fact that at $4.489 \mathrm{~m}$ from the mixing section (plane 2), the flow is more fully developed. A $20 \%$ error is observed from the comparison between slug frequency obtained from CFD and experiment. This may be due to the fact that the experimental measurements were taken over 60 seconds whilst for the CFD 16 seconds.

The translational velocity of the leading Taylor bubble has been calculated for the CFD as well as for the experimental study as shown in Figure 10. The figure illustrates the procedure to calculate the translational velocity of the Taylor bubble for both the CFD and experiment. The results show that translational velocity of the Taylor bubble for the CFD compares well with the experiment.

The lengths of both the liquid slug, Taylor bubble and slug unit are also obtained from CFD which all compared well with experiment. A comparison between the CFD simulation and the experiments is also made based on the void fractions in both the liquid slug and the Taylor bubble. The values obtained are reasonably good as shown in Table $6 \mathrm{~b}$.
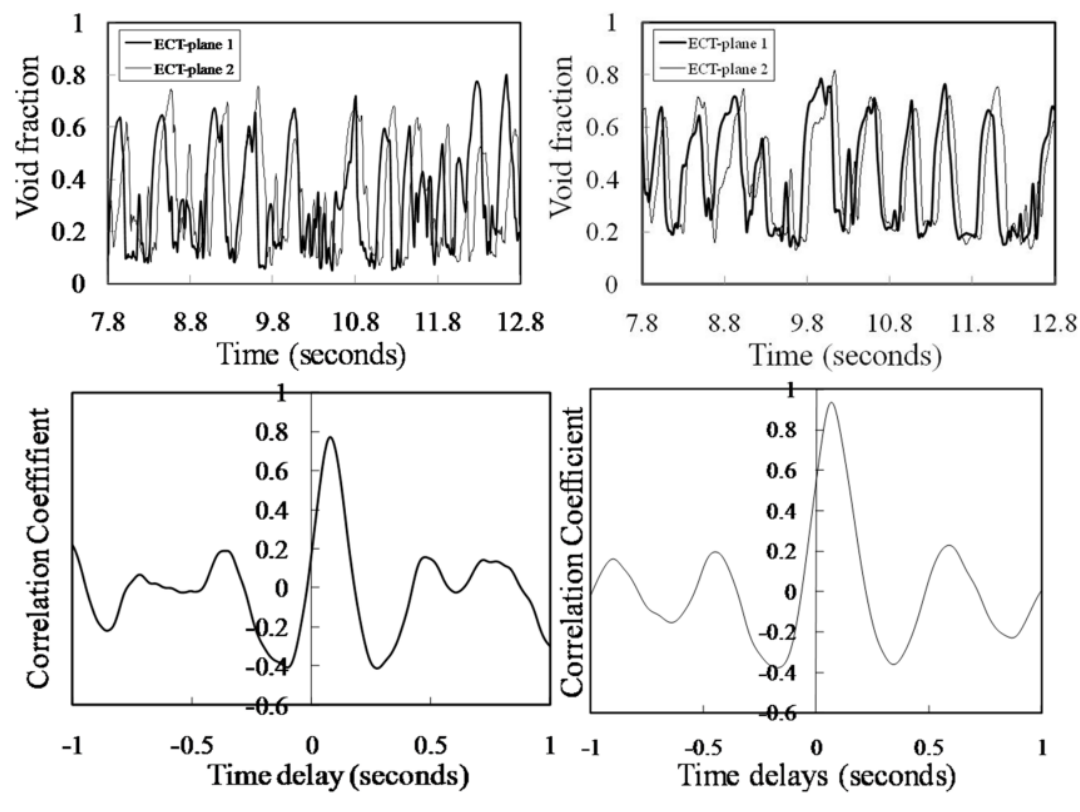

(a) $\mathrm{V}_{\mathrm{TB}}=$ Distance $/$ Time delay $=0.089 / 0.06=1.48 \mathrm{~m} / \mathrm{s}$

(b) $\mathrm{V}_{\mathrm{TB}}=$ Distance $/$ Time delay $=0.089 / 0.056=1.59 \mathrm{~m} / \mathrm{s}$

Figure 10: Time delay of a Tay lor bubble passing through two different measuring locations along the pipe. The liquid and gas superficial velocities are 0.05 and $0.344 \mathrm{~m} / \mathrm{s}$, respectively (a) CFD and (b) Experiment. The initial condition for both CFD and experiment is riser full of (static) liquid. $V_{T B}$ represents the structure velocity of the Tay lor bubble. 
A comparison is also made between experiment and CFD based on static pressure. The value obtained from experiment is $3.42 \times 10^{4} \mathrm{~Pa}$ whilst for the CFD as shown on the pressure contour plot (Figure 11) is $3.37 \times 10^{4} \mathrm{~Pa}$. The simulation under predicts the experiment by 1.5 $\%$. The value obtained from experiment was evaluated as follows:

$$
\Delta P_{\text {Static }}=\rho_{m} g h
$$

Where $\rho_{m}$ is the mixture density and is obtained based on the knowledge of the crosssectional void fraction and $h$ is the height of the riser.

Static Pressure (Pa)

33716

26973.

20229

13480

6743.1

Figure 11: Static pressure contour plot for liquid and gas superficial velocities of 0.05 and $0.344 \mathrm{~m} / \mathrm{s}$, respectively obtained from CFD. The initial condition for both CFD and experiment is riser full of (static) liquid. 


\section{Conclusions:}

A comparison between the results of slug flow characterization obtained from CFD simulation and experiments has been successfully carried out for a $67 \mathrm{~mm}$ internal diameter vertical riser with air and silicone oil as the model fluids and the following conclusions can be drawn:

1) The qualitative comparison between CFD and experiment based on different methods of introducing fluid into the riser liquid and gas superficial velocities of 0.05 and $0.344 \mathrm{~m} / \mathrm{s}$ respectively did not yield any significant difference once the flow reaches steady-state. At steady-state, both the CFD and experiment predict similar behaviours.

2) The slug flow pattern can be considered fully developed at $4.0 \mathrm{~m}$ (60 pipe diameters).

3) A reasonably good agreement between CFD and experiment was obtained. CFD simulation can be used to characterize slug flow parameters with a good level of confidence. However, further parametric studies are required to close some of the gaps between CFD and experimental results.

4) This work confirms the results reported in the literature for the characteristics of slug flow.

5) The best degree of agreement in terms of the slug flow characterization for the large trailing Taylor bubble between CFD and experiment is the void fraction in the Taylor bubble whilst the least is the liquid film thickness. On the other hand, the length of the Taylor bubble and the void fraction in the liquid slug, respectively, represent the best and the least degree of agreement for the leading Taylor bubble between CFD and experiment.

6) The comparison between CFD and experiment based on static pressure is qualitatively good. 


\section{Nomenclature:}

\begin{tabular}{|c|c|}
\hline A & Area $\left[m^{2}\right]$ \\
\hline $\mathrm{F}$ & Frequency $[H$ \\
\hline$V_{T B}$ & Structure velocity $[\mathrm{m} / \mathrm{s}]$ \\
\hline$L_{S U}$ & Length of the slug unit $[\mathrm{m}]$ \\
\hline$L_{S}$ & Length of the liquid slug $[\mathrm{m}]$ \\
\hline$L_{T B}$ & Taylor bubble length $[\mathrm{m}]$ \\
\hline$g$ & Gravitational acceleration $\left[\mathrm{m} / \mathrm{s}^{2}\right]$ \\
\hline$k$ & Kinetic energy of turbulence $\left[\mathrm{m}^{2} / \mathrm{s}^{2}\right]$ \\
\hline $\mathrm{n}$ & number of phases [-] \\
\hline$t$ & Time $[s]$ \\
\hline$u$ & Velocity $[\mathrm{m} / \mathrm{s}]$ \\
\hline$\mu$ & Dynamic viscosity $[\mathrm{kg} / \mathrm{m} . \mathrm{s}]$ \\
\hline$\rho$ & Material density $\left[\mathrm{kg} / \mathrm{m}^{3}\right]$ \\
\hline$\sigma$ & Surface tension $[\mathrm{N} / \mathrm{m}]$ \\
\hline$i, j$ & Space directions \\
\hline$q$ & Phase index \\
\hline
\end{tabular}

\section{ACKNOWLEDGEMENTS}

M. Abdulkadir would like to express sincere appreciation to the Nigerian government through the Petroleum Technology Development Fund (PTDF) for providing the funding for his doctoral studies.

This work has been undertaken within the Joint Project on Transient Multiphase Flows and Flow Assurance, sponsored by the UK Engineering and Physical Sciences Research Council (EPSRC); Advantica; BP Exploration; CD-adapco; Chevron; ConocoPhillips; ENI; ExxonMobil; FEESA; IFP; Institutt for Energiteknikk; Norsk Hydro; PDVSA (INTERVEP); Petrobras; PETRONAS; Scandpower PT; Shell; SINTEF; Statoil and TOTAL. The Authors wish to express their sincere gratitude for their supports. 
References:

[1] A. Clarke, R.I. Issa, A numerical model of slug flow in vertical tubes, Comp. and Fluids, 26 (1997) $395-415$.

[2] Z.S. Mao, A.E. Dukler, 1985. Brief communication: Rise velocity of a Taylor bubble in a train of such bubbles in a flowing liquid, Chemical Engineering Science, 40, 2158 - 2160.

[3] D.J. Nicklin, J.O. Wilkes, J.F. Davidson, 1992. Two-phase flow in vertical tubes, Transaction of Institution of Chemical Engineers, 40, $61-68$.

[4] R.C. Fernandes, R. Semiat, A.E. Dukler, 1983. Hydrodynamics model for gas-liquid slug flow in vertical tubes, AIChE Journal, 29, 981- 989.

[5] Z.S. Mao, A.E. Dukler, 1991. The motion of Taylor bubbles in vertical tubes. II. Experimental data and simulations for laminar and turbulent flow, Chemical Engineering Science, 46, 2055 - 2064.

[6] J. Fabre, A. Line, 1992. Modelling of two-phase slug flow, Annual Review of Fluid Mechanics, 24, 21-46.

[7] B.J. Azzopardi, L.A. Abdulkareem, S. Sharaf, S, M. Abdulkadir, V. Hernandez-Perez, A. Ijioma, 2010. Using tomography to interrogate gas-liquid flow, In: $28^{\text {th }}$ UIT Heat Transfer Congress, Brescia, Italy, 21-23 June.

[8] M. Abdulkadir, V. Hernandez-Perez, S. Sharaf, I.S. Lowndes, B.J. Azzopardi, 2010. Experimental investigation of phase distributions of an air-silicone oil flow in a vertical pipe. World Academy of Science Engineering and Technology (WASET), 61, 52-59.

[9] M. Abdulkadir, D. Zhao, S. Sharaf, L. Abdulkareem, I.S. Lowndes, B.J. Azzopardi, 2011. Interrogating the effect of $90^{\circ}$ bends on air-silicone oil flows using advanced instrumentation, Chemical Engineering Science, 66, 2453 - 2467.

[10] V. Hernandez-Perez, M. Abdulkadir, B.J. Azzopardi, 2011. Grid generation issues in the CFD modelling of two-phase flow in a pipe, The Journal of Computational Multiphase Flow, $3,13-26$.

[11] S.M. Huang, 1995. Impedance sensors-dielectric systems, In R. A. Williams, and M. S. Beck (Eds.), Process Tomography, Cornwall: Butterworth-Heinemann Ltd.

[12] K. Zhu, S. Madhusudana Rao, C. Wang, S. Sundaresan, 2003. Electrical capacitance tomography measurements on vertical and inclined pneumatic conveying of granular solids, Chemical Engineering Science, 58, 4225 - 4245.

[13] M.J. da Silva, S. Thiele, L. Abdulkareem, B.J. Azzopardi, U. Hampel, 2010. Highresolution gas-oil two-phase flow visualization with a capacitance wire-mesh sensor, Flow Measurement and Instrumentation, 21, 191 - 197.

[14] C.W. Hirt, B.D. Nichols, 1981. Volume of Fluid (VOF) Method for the Dynamics of Free Boundaries, Journal of Computational Physics, 39, 201.

[15] V. Hernandez-Perez, 2008. Gas-liquid two-phase flow in inclined pipes, $\mathrm{PhD}$ thesis, University of Nottingham.

[16] S. Lo, D. Zhang, 2009. Modelling of break-up and coalescence in bubbly two-phase flows, The Journal of Computational Multiphase Flow, 1, $23-38$.

[17] STAR-CD, 2009. Version 4.10, STAR-CCM+ Documentation, CD-adapco. 
[18] O. Ubbink, 1997. Numerical prediction of two fluid systems with sharp interfaces, PhD thesis, University of London.

[19] S. Muzaferija, M. Peric, 1999. Computation of free surface flows using interfacetracking and interface-capturing methods, Chap.2 in O. Mahrenholtz and M. Markiewicz (eds.), Nonlinear Water Wave Interaction, Computational Mechanics Publication, WIT Press, Southampton.

[20] J.U. Brackbill, D.B. Kothe, C. Zemach, 1992. A continuum method for modelling surface tension, Journal of Computational Physics, 100, 335 - 354.

[21] B. Launder, D. Spalding, 1974. The numerical computation of turbulent flows, Computational Methods in App. Mech. and Eng., 3, 269 - 289.

[22] A. Ramos-Banderas, R.D. Morales, R. Sanchez-Perez, L. Garcia-Demedices, G. SolorioDiaz, 2005. Dynamics of two-phase downwards flow in submerged entry nozzles and its influence on the two-phase flow in the mold, International Journal of Multiphase Flow, 31, $643-665$.

[23] M. Cook, M. Behnia, 2001. Bubble motion during inclined intermittent flow, International Journal of Multiphase Flow, 22, 543 - 551.

[24] H.K. Versteeg, W. Malalasekera, W., 2007. An Introduction to Computational Fluid Dynamics: the Finite Volume Method, $2^{\text {nd }}$ ed. Pearson Educational Limited.

[25] S.V. Patankar, D.B. Spalding, A calculation procedure for heat, mass and momentum transfer in three dimensional parabolic flows, Int. J. of Heat and Mass Transfer 15 (1972) 1787.

[26] G. Costigan, P.B. Whalley, 1997. Slug flow regime identification from dynamic void fraction measurements in vertical air-water flows, International Journal of Multiphase Flow, $23,263-282$.

[27] L. Shemer, A. Gulitski, D. Barnea, 2004. Velocity field in the Taylor bubble wake measurements in pipes of various diameters, 24nd European Two-phase Flow Group Meeting, Geneva.

[28] Abdulkadir, M., Hernandez-Perez, V., Lowndes, I.S., Azzopardi, B. J., Dzomeku, S., 2014. Experimental study of the hydrodynamic behaviour of slug flow in a vertical riser. Chemical Engineering Science, 106, 60-75. 


\section{Figure captions:}

Figure 13 -D geometry of the computational flow domain showing the location of the recording sections that correspond to the locations of the experimental measurement transducers.

Figure 2 Air-silicone oil mixing section

Figure 3 Computational mesh used for simulations

Figure 4: Cross-sectional view of different sizes of computational grid used for mesh independent study (a) 26400 cells (b) 36000 cells (c) 54,600 cells (d) 76,800 cells (e) 84,000 cells (f) 102,600 cells. Liquid and gas superficial velocities $=0.05$ and $0.344 \mathrm{~m} / \mathrm{s}$, respectively. An initial condition of riser full of (static) liquid was used.

Figure 5: Comparison between experimental data and CFD simulation results at liquid and gas superficial velocities of 0.05 and $0.344 \mathrm{~m} / \mathrm{s}$, respectively. The initial conditions are riser full of (static) liquid and riser full of air, for CFD and experiment, respectively. The time difference observed in the CFD is due to the different times recorded for the Taylor bubble to arrive the measurement locations. Locations $4.4 \mathrm{~m}, 4.489 \mathrm{~m}$ and $4.92 \mathrm{~m}$ corresponds to ECTplane 1, ECT-plane 2 and WMS, respectively.

Figure 6: Comparison of contours of phase distribution at liquid and gas superficial velocities of 0.05 and $0.344 \mathrm{~m} / \mathrm{s}$, respectively for between (a) CFD and (b) WMS and for (c) CFD and (d) ECT. For the CFD and WMS comparison, the liquid and gas phases are represented by red and blue colours, respectively. On the contrary, blue represents gas phase for the ECT. The initial conditions are riser full of (static) liquid and riser full of air, for CFD and experiment, respectively.

Figure 7: Contours of phase distribution (cross-sectional void fraction of gas) for the Taylor bubble obtained at liquid and gas superficial velocities of 0.05 and $0.344 \mathrm{~m} / \mathrm{s}$, respectively from (a) CFD and (b) WMS and for (c) CFD and (d) ECT. For the CFD and WMS comparison, the liquid and gas phases are represented by red and blue colours, respectively. On the contrary, blue represents gas phase for the ECT. The initial conditions are riser full of (static) liquid and riser full of air, for CFD and experiment, respectively.

Figure 8: Velocity field around the (a) Taylor bubble (b) Wake region of the Taylor bubble at liquid and gas superficial velocities of 0.05 and $0.344 \mathrm{~m} / \mathrm{s}$, respectively. The initial conditions are riser full of (static) liquid and riser full of air, for CFD and experiment, respectively.

Figure 9: A plot showing a combination of a large trailing Taylor bubble (start-up) and leading train of smaller Taylor bubbles (steady-state) at liquid and gas superficial velocities = 0.05 and $0.344 \mathrm{~m} / \mathrm{s}$, respectively). The initial condition for both CFD and experiment is riser full of (static) liquid. 
Figure 10: Time delay of a Taylor bubble passing through two different measuring locations along the pipe. The liquid and gas superficial velocities are 0.05 and $0.344 \mathrm{~m} / \mathrm{s}$, respectively (a) CFD and (b) Experiment. The initial condition for both CFD and experiment is riser full of (static) liquid.

Figure 11: Static pressure contour plot for liquid and gas superficial velocities of 0.05 and $0.344 \mathrm{~m} / \mathrm{s}$, respectively obtained from CFD. The initial condition for both CFD and experiment is riser full of (static) liquid.

\section{Table captions:}

Table 1 Table of flowchart for experimental measurement used to obtain the parametric characterisation of the slug flow regime

Table 2 Properties of the fluids

Table 3: The results obtained from the CFD mesh independence studies. Liquid and gas superficial velocities $=0.05$ and $0.344 \mathrm{~m} / \mathrm{s}$, respectively. An initial condition of riser full of (static) liquid was used.

Table 4: Interrogating flow development in a vertical $67 \mathrm{~mm}$ internal diameter and $6 \mathrm{~m}$ long riser. Riser initially full of (static) liquid, and the liquid and gas flows set to liquid and gas superficial velocities of 0.05 and $0.344 \mathrm{~m} / \mathrm{s}$, respectively

Table 5a: Comparison between the CFD and experiments for the large trailing Taylor bubble (Start-up) at liquid and gas superficial velocities of 0.05 and $0.344 \mathrm{~m} / \mathrm{s}$, respectively). The initial condition for both CFD and experiment is riser full of (static) liquid.

Table 5b: Comparison between the CFD and experiments for the large trailing Taylor bubble (Start-up) at liquid and gas superficial velocities of 0.05 and $0.344 \mathrm{~m} / \mathrm{s}$, respectively). The initial condition for both CFD and experiment is riser full of (static) liquid.

Table 6a: Comparison between the CFD and experiments for the leading Taylor bubble (steady-state)/ (fully developed) at liquid and gas superficial velocities of 0.05 and $0.344 \mathrm{~m} / \mathrm{s}$, respectively). The initial condition for both CFD and experiment is riser full of (static) liquid.

Table 6b: Comparison between the CFD and experiments for the leading Taylor bubble (steady-state)/ (Fully developed) at liquid and gas superficial velocities of 0.05 and 0.344 $\mathrm{m} / \mathrm{s}$, respectively). The initial condition for both CFD and experiment is riser full of (static) liquid. 